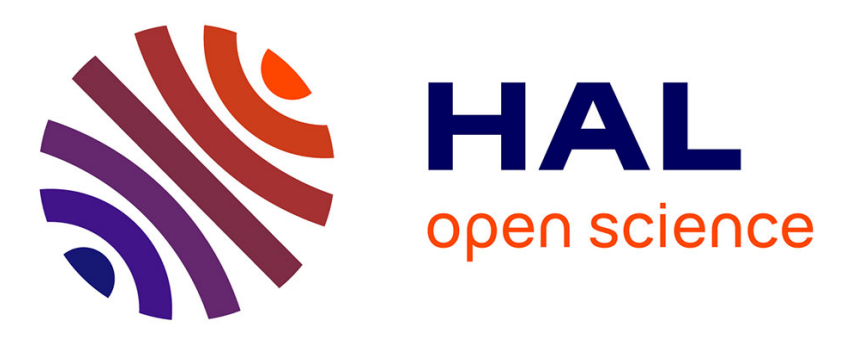

\title{
Polymer foaming with chemical blowing agents: Experiment and modeling
}

José Antonio Reglero Ruiz, Michel Vincent, Jean-François Agassant, Tarik Sadik, Caroline Pillon, Christian Carrot

\section{> To cite this version:}

José Antonio Reglero Ruiz, Michel Vincent, Jean-François Agassant, Tarik Sadik, Caroline Pillon, et al.. Polymer foaming with chemical blowing agents: Experiment and modeling. Polymer Engineering and Science, 2015, 55 (9), pp.2018-2029. 10.1002/pen.24044 • hal-01102122

HAL Id: hal-01102122

https://hal-mines-paristech.archives-ouvertes.fr/hal-01102122

Submitted on 16 Oct 2015

HAL is a multi-disciplinary open access archive for the deposit and dissemination of scientific research documents, whether they are published or not. The documents may come from teaching and research institutions in France or abroad, or from public or private research centers.
L'archive ouverte pluridisciplinaire $\mathbf{H A L}$, est destinée au dépôt et à la diffusion de documents scientifiques de niveau recherche, publiés ou non, émanant des établissements d'enseignement et de recherche français ou étrangers, des laboratoires publics ou privés. 


\title{
Polymer foaming with Chemical Blowing Agents: Experiment and modeling
}

\author{
José Antonio Reglero Ruiz ${ }^{1}$, Michel Vincent ${ }^{1}$, Jean-François Agassant ${ }^{1}$, Tarik Sadik ${ }^{2}$, \\ Caroline Pillon ${ }^{2}$ and Christian Carrot ${ }^{2}$ \\ ${ }^{1}$ MINES ParisTech - Centre de Mise en Forme des Matériaux (CEMEF) \\ UMR CNRS 7635 \\ 1, rue Claude Daunesse, CS 10207, 06904 - Sophia Antipolis Cedex, France. \\ ${ }^{2}$ Ingénierie des Matériaux Polymères (IMP) \\ UMR CNRS 5223 \\ Université de Saint-Etienne, Jean Monnet, F-42023, Saint-Etienne, France. \\ Université de Lyon, F-42023, Saint-Etienne, France.
}

\begin{abstract}
An experimental and theoretical analysis of the polymer foaming process using different chemical blowing agents (CBA) was performed. A simple experiment was designed to analyze the foaming process of polypropylene (PP)/CO $\mathrm{CO}_{2}$ system under different pressure conditions using several chemical foaming agents. The expansion ratio was measured both by direct observation and from optical measurements and image analysis, showing a good agreement. A single bubble simulation based on relevant Differential Scanning Calorimetry (DSC) and Thermo-Gravimetrical Analysis (TGA) experiments, assuming each CBA particles as a nucleation site and accounting for gas diffusion in the surrounding polymer matrix has been built. The sensitivity of the model to physical and processing parameters has been tested. The calculation results are compared to the experiments and open the route to a simplified method for evaluating the efficiency of chemical blowing agents.
\end{abstract}

\section{1 - Introduction}

The foaming process to produce microcellular thermoplastics has been widely analysed in the last decades. Microcellular plastics are generally formed by cell nucleation and growth of bubbles in the polymer matrix. Chemical blowing agents (CBA) or physical blowing agents (PBA) are used to introduce the gas that creates the cellular structure.

A typical polymer foaming process involves several steps: the dissolution under an elevated pressure of a gas blowing agent (PBA or CBA) in the molten polymer, the nucleation of a population of gas clusters in the supersaturated solution upon the release of pressure to the ambient pressure and finally the growth of nucleated bubbles in the polymer to their ultimate equilibrium size. The final foam density depends on the original gas loading, the gas fraction which remains dissolved in the polymer matrix when it solidifies, the gas losses to the environment, and the depressurization rate. The cell size and cell size distribution depend on the kinetics of nucleation, the bubble growth process following nucleation and the coalescence during expansion.

Different steps can be considered when processing such materials. First the polymer/gas solution formation, second the microcellular nucleation, and finally the cell growth and the resulting density reduction. In the first stage, the polymer/gas solution formation is accomplished by saturating a polymer under a high gas pressure, forming a single-phase supersaturated solution governed by the gas dissolution in the polymer matrix which is a function of pressure and, at a lesser extent, of 
temperature. Numerous studies have been carried out analysing the dependence of the solubility of gas in several polymers, mainly $\mathrm{CO}_{2}$ in polypropylene $[1,2,3]$.

In the second stage, it is necessary to submit the polymer/gas solution to a thermodynamic instability to nucleate microcells. This nucleation can be achieved by lowering the solubility of the solution through the temperature and the pressure of the system. Usually, a rapid pressure drop produces a high nucleation rate in the polymer matrix and in the ideal case this nucleation occurs instantaneously.

In plastic foaming, nucleation refers to the process of generating gas bubbles in a polymer melt through a reversible thermodynamic process. Creation of small bubbles always leads to a free energy increase and they are in an unstable equilibrium with the environment. In the classical nucleation theory, there is a critical nucleus, which defines the minimum radius for a bubble to growth. Nucleated bubbles which size is larger than the critical nucleus radius will survive, whereas those smaller will collapse. Cell nucleation can occur homogenously or heterogeneously. The heterogeneous nucleation is usually 100 to 1000 times more favourable than homogeneous nucleation. Several additives or organic charges can be employed as nucleation sites in polymer foaming processes $[4,5]$.

Once the cells are nucleated, they continue to expand by diffusion of the dissolved gas from the polymer matrix into the bubbles. In this stage of the process, a deep knowledge of the physical parameters that govern the diffusion properties of gas-polymer systems is necessary $[6,7,8,9]$. The cells grow reducing the polymer density as the gas molecules diffuse into the nucleated cells. The rate at which the cells grow is limited by the diffusion rate and the rheology of the polymer/gas solution. The cell growth process is controlled also by the time allowed for the cells to grow before solidification, the temperature and pressure of the system, the presence of other bubbles, etc... [10].

As explained before, there are two main processes to produce microcellular polymeric foams, basically depending on the way to introduce the gas into the polymer matrix. In the physical foaming agents (PBA) process, the gases are introduced directly into the barrel of an extruder or of the plasticating unit of an injection molding machine, in the polymer matrix. This method, (Mucell ${ }^{\circledast}$ process), has been extensively analysed by Park and Tomasko [11, 12, 13]. Several types of PBAs such as $\mathrm{CO}_{2}, \mathrm{~N}_{2}$ [14], chlorofluorocarbons or argon have been used with different polymer resins such as polypropylene, polyethylene or polystyrene [15]. Although PBAs can be employed both in extrusion and injection processes, the foaming injection molding process using $\mathrm{CO}_{2}$ or $\mathrm{N}_{2}$ is commonly used. However, PBA foaming needs special equipment such as gas dosage unit and controller, gas injector, a specially designed screw and a high-pressure gas source.

The second group of foaming processes involves the use of chemical blowing agents (CBA) that can liberate gases under certain processing conditions either due to chemical reaction or thermal decomposition. Most CBAs produce nitrogen $\left(\mathrm{N}_{2}\right)$ or carbon dioxide $\left(\mathrm{CO}_{2}\right)$ after decomposition [16, 17, 18]. CBAs reactions can be endothermic or exothermic. Azodicarbonamide is the most representative exothermic $\mathrm{CBA}$, commonly having a high gas yield, with decomposition temperatures between $170^{\circ} \mathrm{C}$ and $200^{\circ} \mathrm{C}$ [19]. Sodium bicarbonate and zinc bicarbonate are the most common endothermic blowing agents [20]. The injection-moulded plastics parts foamed by CBAs have reduced density, reduction of sink marks and are easy to process, but the bubbles are larger than that obtained with PBA, leading in principle to lower mechanical properties. 
Both foaming processes present different physical scenarios. In the case of PBA foaming process the formation of a single gas-polymer supersaturated phase depends only on the saturation pressure and temperature of the system, but as said before, the temperature and pressure evolutions in the barrel can be difficult to control, so it is not straight forward to determine the total quantity of gas diluted in the polymer just before the nucleation and expansion process. In an ideal scenario, the gas dissolution process only occurs in the screw/barrel system, whereas the nucleation and growth phenomena take place during or after mould filling. Both processes are completely independent and separated.

In the case of CBA foaming process, it can be considered in a first approximation that the decomposition reaction is complete in the screw-barrel system, and that all the gas is generated, diffused and solubilised into the polymer matrix. The solubilisation of the gas into the polymer depends of the pressure in the plasticization unit but also of the ratio between the plasticization time and the diffusion time. If the decomposition reaction is not completed in the plasticization unit, the physical system to analyse becomes more complicated. Part of the gas remains unreacted in the CBA particles, and the foaming process begins even when all the gas has not been totally created.

This paper is focused on CBAs foaming process. The physical evolution of the polymer-gas system depends strongly of the temperature, pressure and kinetics of the chemical reactions. A simple experiment has been designed to analyse the foaming expansion as a function of time of a polypropylene containing three types of CBA, in static conditions (no flow). The expansion ratio has been measured by direct observation and from optical measurements and image analysis. A single bubble simulation based on DSC and TGA experiments, assuming each CBA particle as a nucleation site and accounting for gas diffusion in the surrounding polymer matrix has been built. The sensitivity of the model to physical and processing parameters has been tested and the results are compared to the experiments.

\section{2 - Experimental}

\section{1 - Materials}

The polypropylene compound was a $12 \%$ mineral filled elastomer modified polypropylene (SUMIKA PP) with a melt flow index of $65 \mathrm{~g} / 10 \mathrm{~min}$ (ISO R1133), a Newtonian plateau viscosity of $500 \mathrm{~Pa} \cdot \mathrm{s}$ at $210^{\circ} \mathrm{C}$, determined from rotational rheological measurements, and a density of $0.91 \mathrm{~g} / \mathrm{cm}^{3}$. Three different endothermic chemical blowing agents Hydrocerol ${ }^{\circledR}$ (CLARIANT) referred as CBA-818, CBA828 and CBA-848 were analysed. These foaming agents are PE-based compounds with reactive elements (typically citric acid, sodium bicarbonate or a mix of both components). Table 1 presents the different CBA's employed and the weight concentration (wt. \% respect to PE matrix) of reactive elements. In the following, CBA refers to the compound and not to the reactive elements only.

The Hydrocerol ${ }^{\circledast}$ foaming agent has been extensively employed in the last few years [21-25]. These chemical agents, with decomposition temperatures between $160{ }^{\circ} \mathrm{C}$ and $210{ }^{\circ} \mathrm{C}$, can be added directly into the hopper of an injection moulding machine in the form of pellets in proportions from $1 \%$ to 4 wt. \%. 


\begin{tabular}{|c|c|c|c|}
\hline CBA & Matrix & Reactive elements & $\begin{array}{c}\text { Proportion } \\
\text { (wt \%) }\end{array}$ \\
\hline 1 & $P E$ & Citric acid + sodium bicarbonate & $35+35$ \\
\hline 2 & $P E$ & Citric acid & 70 \\
\hline 3 & $P E$ & Sodium bicarbonate & 70 \\
\hline
\end{tabular}

Table 1 - Chemical composition of the CBA particles

Thermal characterization was carried out to determine the polypropylene fusion temperature and the decomposition temperatures of each reaction of the reactive elements included in the CBA pellets. Results are presented in figure 1 . A heating rate of $6^{\circ} \mathrm{C} / \mathrm{min}$ was chosen to assure the same heating rate as in the experimental foaming expansions.

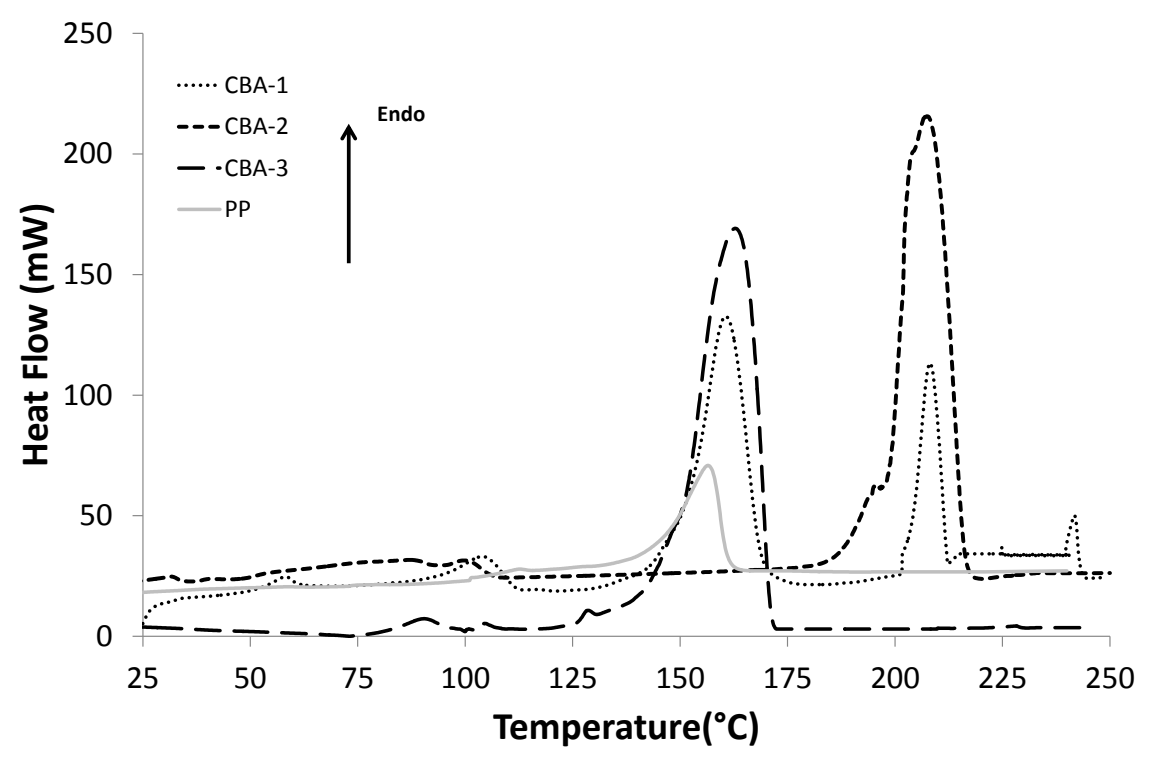

Figure 1-DSC curve of the chemical foaming agents and of the polypropylene compound. Constant heating rate of $6^{\circ} \mathrm{C} / \mathrm{min}$, from ambient temperature to $250^{\circ} \mathrm{C}$.

The peak between $160{ }^{\circ} \mathrm{C}$ and $170{ }^{\circ} \mathrm{C}$ corresponds to the melting of polypropylene. For the three CBAs, the small peak around $90{ }^{\circ} \mathrm{C}$ corresponds to the PE melting temperature. For the CBA-818 and CBA-848, the peaks between $150{ }^{\circ} \mathrm{C}$ and $175{ }^{\circ} \mathrm{C}$ correspond to sodium bicarbonate decomposition reaction. A peak between $190^{\circ} \mathrm{C}$ and $220^{\circ} \mathrm{C}$ caused by the decomposition of citric acid is visible for CBA-828 and CBA-818. Finally, a small peak about $240{ }^{\circ} \mathrm{C}$ takes place in the CBA-818, caused by the coupling reaction of the remaining sodium bicarbonate and citric acid. This third reaction is only important at higher heating rates (above $20^{\circ} \mathrm{C} / \mathrm{min}$ ). For low heating rates, the importance of this reaction is negligible, as it can be seen in figure 1 . All the decomposition reactions of the CBAs start after the polypropylene fusion, which assures that the gas obtained from the CBA can be diluted in the melted matrix.

TGA measurements were carried out to determine the quantity of gas released by the reactive elements in the CBA particles (figure 2). The relative weight loss refers to the original weight of the granule containing $30 \mathrm{wt}$. \% of polyethylene and $70 \mathrm{wt} . \%$ of reactive elements. This loss is associated to the gas escaping the sample, assuming that the pressure conditions do not allow any gas dissolution in the polyethylene. 


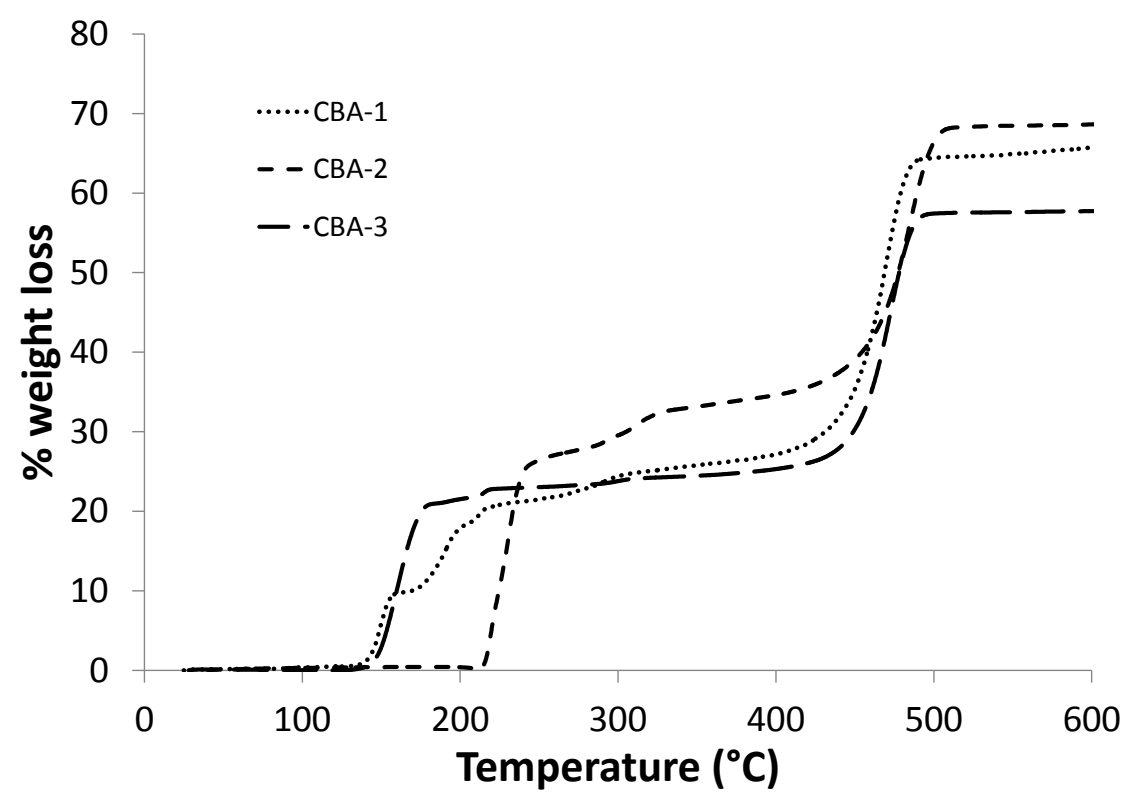

Figure 2 - TGA curve of the chemical foaming agents (heating ramp $10^{\circ} \mathrm{C} / \mathrm{min}$ from ambient temperature to $600^{\circ} \mathrm{C}$ )

The TGA curve of CBA-848 shows that the decomposition reaction of sodium bicarbonate begins at $150{ }^{\circ} \mathrm{C}$, reaching a weight percentage of created gas around $24 \%$ at the end of the reaction, at about $210{ }^{\circ} \mathrm{C}$. In the case of $\mathrm{CBA}-828$, the decomposition reaction of citric acid begins at $215^{\circ} \mathrm{C}$ and ends around $300{ }^{\circ} \mathrm{C}$, with a weight percentage of gas created about $35 \%$. Finally, the CBA-818 presents a first decomposition reaction which begins at $150{ }^{\circ} \mathrm{C}$. The citric acid decomposition reaction is probably coupled with the sodium bicarbonate reaction, as it can be observed in the small change in the slope about $200{ }^{\circ} \mathrm{C}$. The maximum quantity of gas generated at the end of the decomposition reactions is about $28 \mathrm{wt} . \%$ at $300^{\circ} \mathrm{C}$. In all the cases, the PE decomposition begins at $450{ }^{\circ} \mathrm{C}$.

It is possible to obtain the evolution of the total quantity of moles of created gas from the stoichiometry of the decomposition reactions. The sodium bicarbonate decomposition can be described as follows (reaction 1):

$$
2 \mathrm{NaHCO}_{3} \rightarrow \mathrm{Na}_{2} \mathrm{CO}_{3}+\mathrm{H}_{2} \mathrm{O}+\mathrm{CO}_{2}
$$

The citric acid decomposition is (reactions 2 and 3):

$$
\begin{aligned}
& \mathrm{C}_{6} \mathrm{H}_{8} \mathrm{O}_{7} \rightarrow \mathrm{C}_{6} \mathrm{H}_{6} \mathrm{O}_{6}+\mathrm{H}_{2} \mathrm{O} \\
& \mathrm{C}_{6} \mathrm{H}_{6} \mathrm{O}_{6} \rightarrow \mathrm{C}_{5} \mathrm{H}_{6} \mathrm{O}_{4}+\mathrm{CO}_{2}
\end{aligned}
$$

Finally, a coupling reaction occurs when the sodium bicarbonate and citric acid react together to produce $\mathrm{CO}_{2}$ and $\mathrm{H}_{2} \mathrm{O}$ (reaction 4):

$$
\mathrm{C}_{6} \mathrm{H}_{8} \mathrm{O}_{7}+3 \cdot \mathrm{NaHCO}_{3}->\mathrm{Na}_{3} \mathrm{C}_{6} \mathrm{H}_{5} \mathrm{O}_{7}+3 \cdot \mathrm{H}_{2} \mathrm{O}+3 \cdot \mathrm{CO}_{2}
$$

In CBA-848 and CBA-828 only reactions 1 and 2 occur, respectively. As our experiments were carried out at $T<20{ }^{\circ} \mathrm{C} / \mathrm{min}$, the coupling reaction (4) for CBA-818 is neglected. According to the composition given in Table $1,1 \mathrm{~g}$ of CBA contains $0.7 \mathrm{~g}$ of reactive element. The gas escaping the sample is composed both of $\mathrm{CO}_{2}$ (molar mass of $48 \mathrm{~g}$ ) and $\mathrm{H}_{2} \mathrm{O}$ (molar mass of $18 \mathrm{~g}$ ). From the stoichiometry of the reactions it is then possible to obtain the evolution of the number of moles of gas per $\mathrm{g}$ of CBA generated during the decomposition reaction (figure 3 ). It is expected that after foaming and cooling of the samples, the $\mathrm{H}_{2} \mathrm{O}$ remains in the samples as condensed water vapor. 


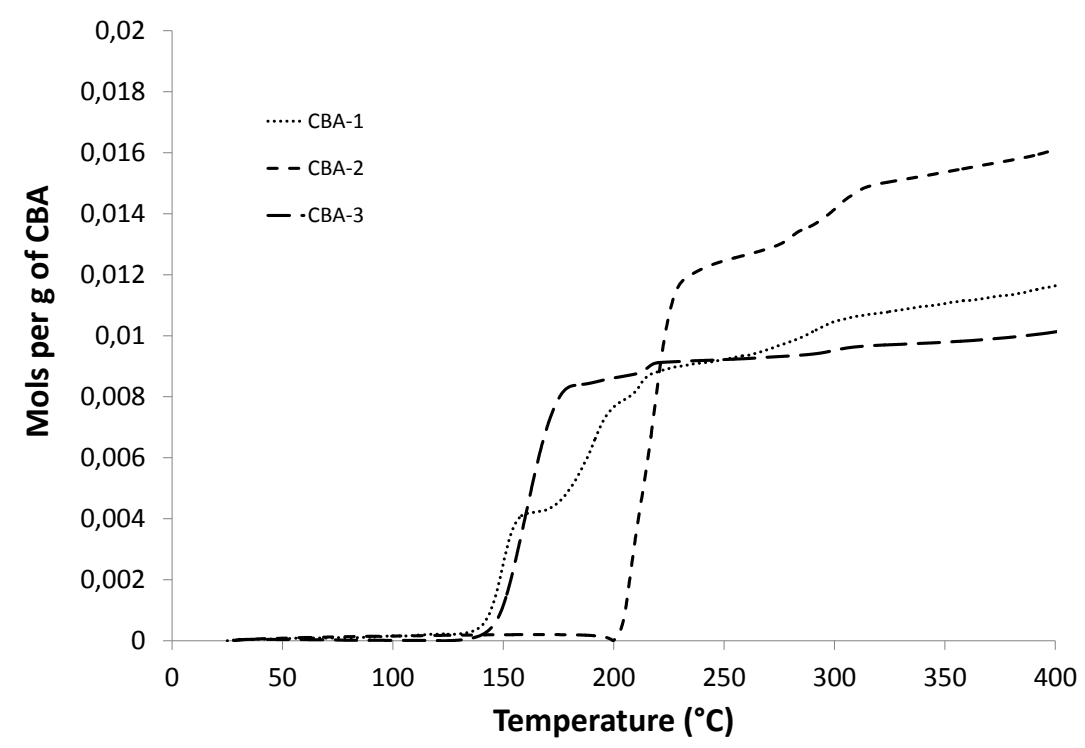

Figure 3-Quantity of gas created during the decomposition of the reactive elements in the CBA particles

\section{2 - Foaming experiment}

The objective is to analyze the foaming behavior of different CBA/PP samples, obtained by mixing the three CBAs with PP granules in the same proportions as in injected samples. These materials are foamed in a steel mold and the expansion ratio and cellular structure will be analyzed.

\subsubsection{Sample preparation and characterization}

The challenge is to mix the components without activating the chemical reactions. A solid sample was fabricated starting from PP and CBA powders. Powders were mixed at room temperature in a fixed proportion of $98 \mathrm{wt}$. \% of polypropylene and $2 \mathrm{wt}$. \% of CBA. Then, cylindrical samples of $9 \mathrm{~mm}$ height $\left(h_{i}\right)$ and $20 \mathrm{~mm}$ diameter $(\phi)$ were fabricated in a steel mold by compression under a pressure of $20 \mathrm{MPa}$ at $60^{\circ} \mathrm{C}$ for $30 \mathrm{~min}$. A total number of six samples, three groups of two samples with the same CBA, were fabricated, with a volume $V_{i}$ of $2.83 \mathrm{~cm}^{3}$. The density of all the samples $\left(\rho_{\text {sample }}\right)$ was about $0.87 \mathrm{~g} / \mathrm{cm}^{3}$, with a densification value up to $99.9 \%$, calculated as:

$$
\text { Densification }=100 *\left(\frac{\rho_{\text {sample }}}{\rho_{P P}}\right)
$$

taking $\rho_{\mathrm{PP}}=0.91 \mathrm{~g} \cdot \mathrm{cm}^{-3}$ as the density of the solid PP.

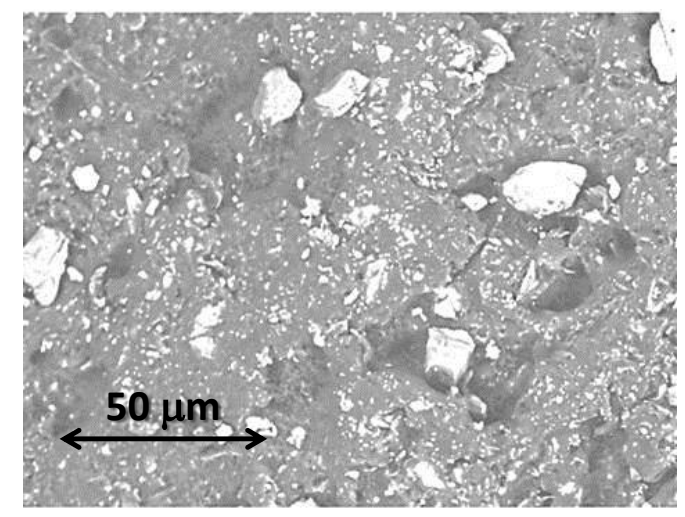

Figure 4-SEM micrograph of the precursor foaming material 
Figure 4 presents a typical SEM micrograph of the sample surface showing the distribution of the foaming agent (white particles) in the polypropylene matrix. The average particle size can be calculated by image analysis, using the Image ${ }^{\circledR}$ software. The minimal observable size is $1 \mu \mathrm{m}$. After binarization of SEM images (figure 5a), the apparent particle radius distribution is obtained and represented as a histogram (figure $5 b$ ).
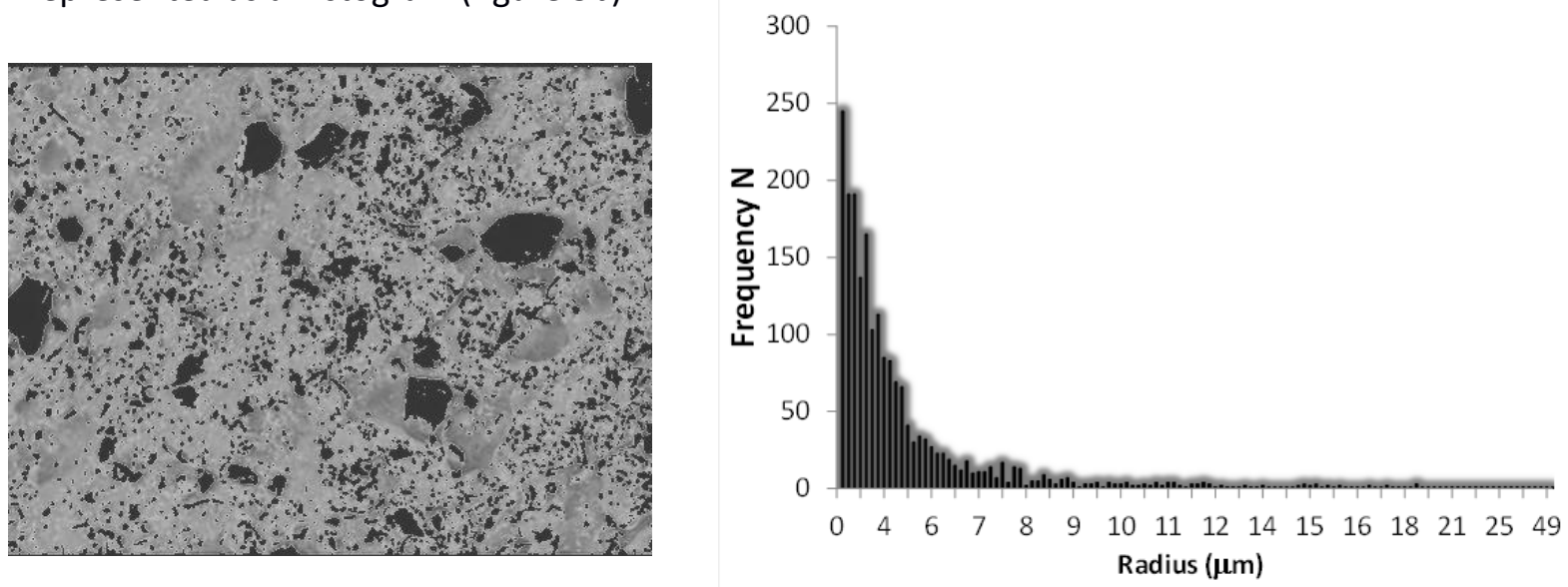

Figure 5 - Calculation of the CBA particle average size

\section{a) Binarized image b) Resulting histogram}

The number average radius $\bar{R}$ and the number average volume $\bar{V}$ can be obtained assuming a spherical geometry of the CBA particles, which is far from reality (equations (6) and (7)):

$$
\begin{gathered}
\dot{R}=\frac{\sum_{i=1}^{N} n_{i} R_{i}}{\sum_{i=1}^{N} n_{i}} \\
\dot{V}=\frac{\sum_{i=1}^{N} n_{i} R_{i}^{3}}{\sum_{i=1}^{N} n_{i}} \frac{4 \pi}{3}
\end{gathered}
$$

where $\mathrm{N}$ represents the total number of particles $(\mathrm{N}=1800)$.

The average value of the reactive agent particle radius is $\bar{R}=4.46 \mu \mathrm{m}$ and the average volume is $\bar{V}$ $2.80 \cdot 10^{-9} \mathrm{~cm}^{3}$. This calculation was performed in three different SEM micrographs, with a dispersion value of $\pm 10 \%$.

Assuming each CBA particle contains 70 wt. \% of reactive agent and 30 wt. \% of low-density PE, and using the mix law (with $\rho_{\text {reactive agent }} \approx 2 \mathrm{~g} / \mathrm{cm}^{3}$ and $\rho_{\text {LDPE }}=0.9 \mathrm{~g} / \mathrm{cm}^{3}$ ), the density of a CBA particle is $1.67 \mathrm{~g} \cdot \mathrm{cm}^{-3}$, which leads to an average mass of a reactive agent particle of $4.70 \cdot 10^{-9} \mathrm{~g}$. The total mass of reactive agents in the sample (mass of $2.5 \mathrm{~g}$ ) is obtained knowing that each sample contains $2 \mathrm{wt}$. $\%$ of $\mathrm{CBA}$, in which the reactive agents represent $70 \mathrm{wt}$ \% $(0.035 \mathrm{~g})$. The total number of reactive agent particles $\left(N_{p}\right)$ in the solid sample is obtained simply by the ratio between the total mass of reactive agent in the sample and the average mass of a reactive agent particle: $0.035 / 4.70 \cdot 10^{-9}=7.45$ $10^{6}$.

Using the same procedure, it is possible to obtain the minimum distance between each particle $(\ell)$, from the previous binarized image (figure 5a). The resulting histogram is presented in figure 6 , together with the expression to calculate the number average valuel. 


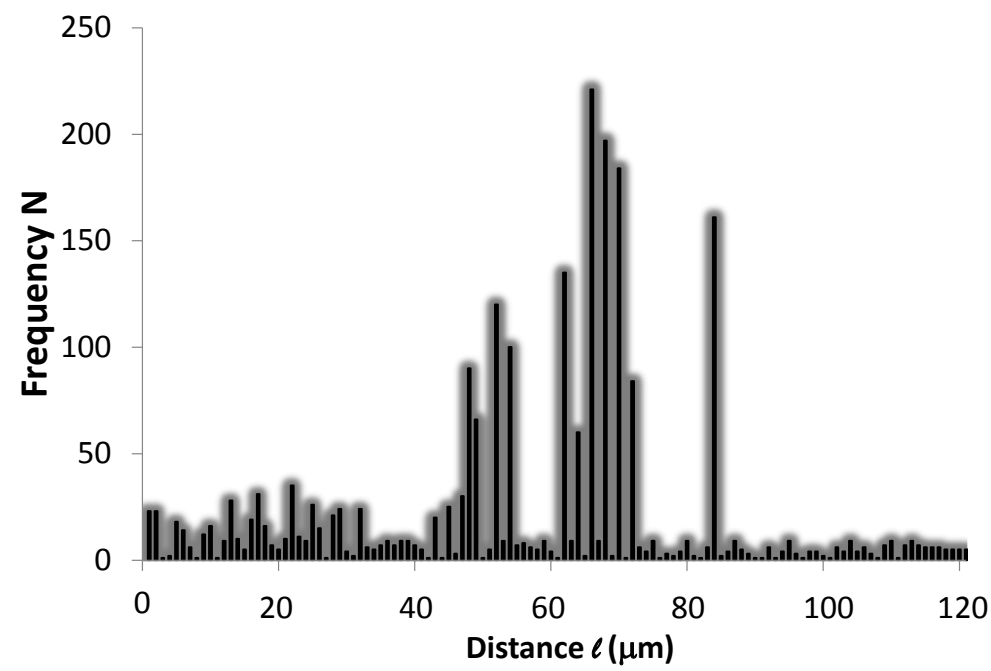

Figure 6-Resulting histogram of the calculation of distance between particles

$$
\hat{l}=\frac{\sum_{i=1}^{N} n_{i} l_{i}}{\sum_{i=1}^{N} n_{i}}
$$

The determination of $l$ from equation (8) gives a result of $74 \mu \mathrm{m}$. Another way for calculating $l$ is to assume a uniform distribution of the reactive agent particles in the solid sample using crystallographic considerations. Considering for example a primitive cubic (PC) Bravais lattice, the number of reactive agent particles in the cubic cell $\left(N_{p}{ }^{\text {cell }}\right)$ is 1 . The determination of the distance $l$ is related to the volume of the solid sample $V_{i}$, the number of reactive agent particles in each cubic cell $N_{P}{ }^{\text {cell }}$ and the total number of reactive agent particles $N_{P}$ through the expression:

$$
\frac{i^{3} N_{P}}{N_{P}^{c e l l}}=V_{i}
$$

Similar calculations can be carried out for the body-centered cubic (BCC) and face-centered cubic (FCC) bravais lattices, in which the number of reactive particles in each cubic cell, is 2 and 4 , respectively. Table 2 presents the results of the three calculations, taking $N_{p}=7.45 \cdot 10^{6}$ and $V_{i}=2.83$ $\mathrm{cm}^{3}$.

\begin{tabular}{|c|c|c|}
\hline Bravais lattice & $\boldsymbol{N}_{\boldsymbol{P}}{ }^{\text {ell }}$ & $\bar{\ell}(\boldsymbol{\mu m})$ \\
\hline$P C$ & 1 & 76 \\
\hline$F C C$ & 2 & 84 \\
\hline$B C C$ & 4 & 87 \\
\hline
\end{tabular}

Table 2 - Average distance between CBA particles from crystallographic calculations

The average initial distance between reactive agent particles is between $76 \mu \mathrm{m}$ and $87 \mu \mathrm{m}$ which is similar to the value obtained from the binarized image. This distance $l$ will increase during the expansion process.

\subsubsection{Foaming experiment under pressure}

Figure 7 presents the scheme of the foaming expansion experiment designed to analyze the behavior of the polypropylene/gas systems. The solid sample, with a number of reactive agent particles $N_{P}$, has an initial height $h_{i}$ and an initial volume $V_{i}$, and it is placed in a reservoir under an external pressure $P_{\text {ext }}$. The reservoir is made of steel, with a thickness of $5 \mathrm{~mm}$ and a height of $200 \mathrm{~mm}$. The inner diameter is $20 \mathrm{~mm}$. The external pressure is applied with a weight deposited on a circular steel 
cap, with a diameter a little bit lower than the inner cylinder diameter. The device is introduced in an oven at a temperature $T$ during a time $t$. A type $\mathrm{K}$ thermocouple is introduced in the sample to monitor the evolution of the temperature. Another one is located inside the oven. At the end of the heating step, the device is removed from the oven and cooled down at ambient air. When cooling is finished the weight is removed. The foamed sample has a final height $h_{f}$, a final volume $V_{f}$, and a cellular structure with a cell density $N_{c}$ and an average cell radius $R$. The height increase during the foaming process is measured optically with a recording camera, with a precision of $\pm 0.5 \mathrm{~mm}$. It is important to mention that the temperature will vary differently as a function of time at different points of the sample, due to heat conduction from the oven. This means also that the foaming develops heterogeneously inside the sample, starting in the sample edges and propagating towards the core.
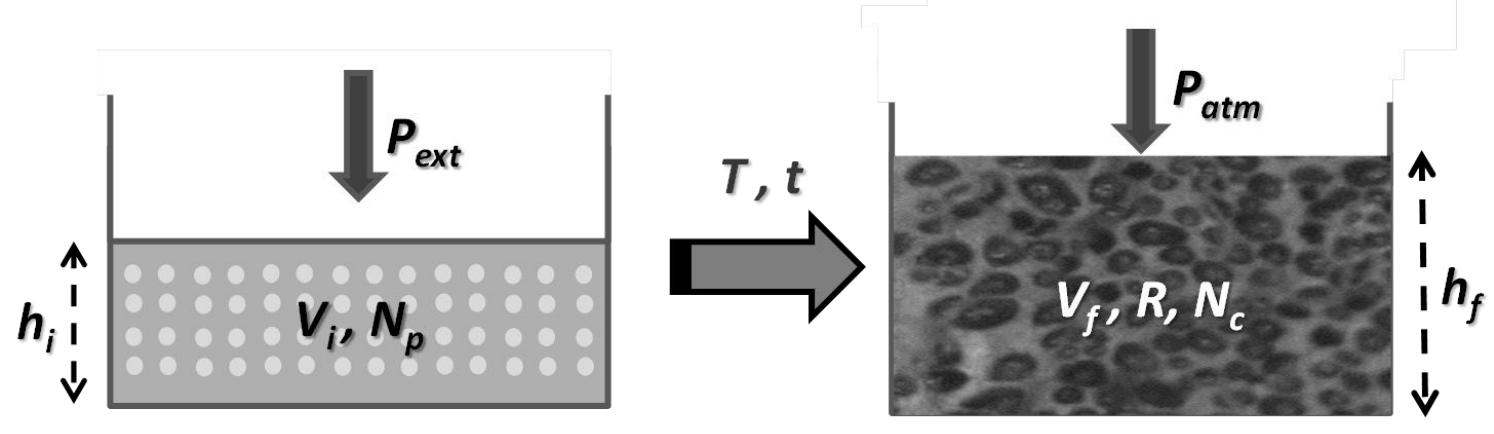

Figure 7 -Scheme of the foaming expansion experiment

Two external pressures were tested to evaluate their influence on the expansion rate, gas diffusion and final pore radius: $0.25 \mathrm{MPa}$ (samples 1-1, 2-1 and 3-1) and 0.5 MPa (samples 1-2, 2-2 and 3-2).

\subsubsection{Results and discussion}

Figure 8 shows the evolution of the temperature with time. The sample and oven temperatures are not equal until the last part of the experiment. The average heating ramp of the sample temperature is about $6^{\circ} \mathrm{C} / \mathrm{min}$, considering a total heating time of $32 \mathrm{~min}$ from ambient temperature to $210^{\circ} \mathrm{C}$.

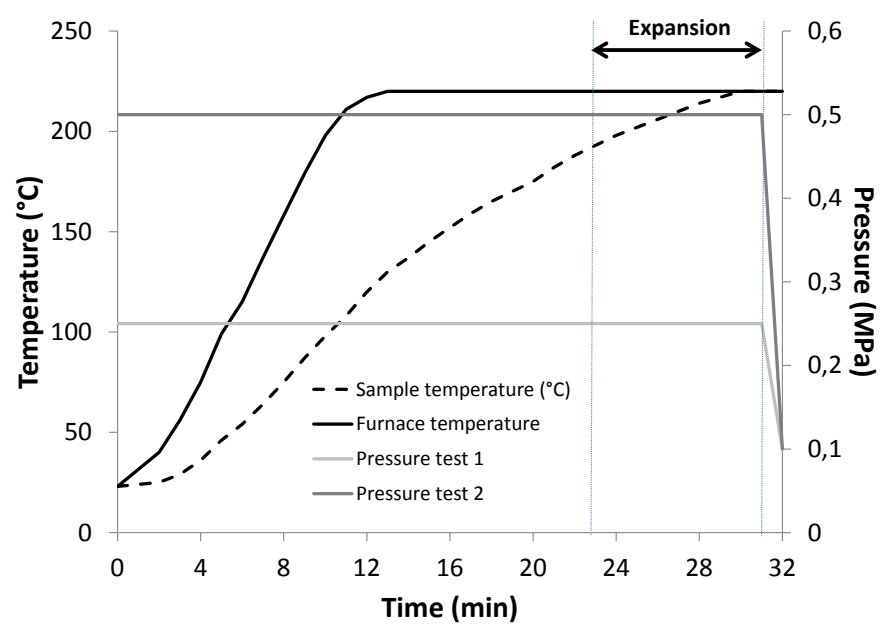

Figure 8-Evolution of the height of each sample during the expansion process 
The measurement of the height variation started when the sample temperature reached $180{ }^{\circ} \mathrm{C}$, slightly above the melting point of the PP, which is located between $160^{\circ} \mathrm{C}$ and $170^{\circ} \mathrm{C}$ according to DSC data (see figure 1). Figure 9 presents the samples height evolution from the beginning of the expansion measurements (about 23 min after starting the experience, see figure 8).

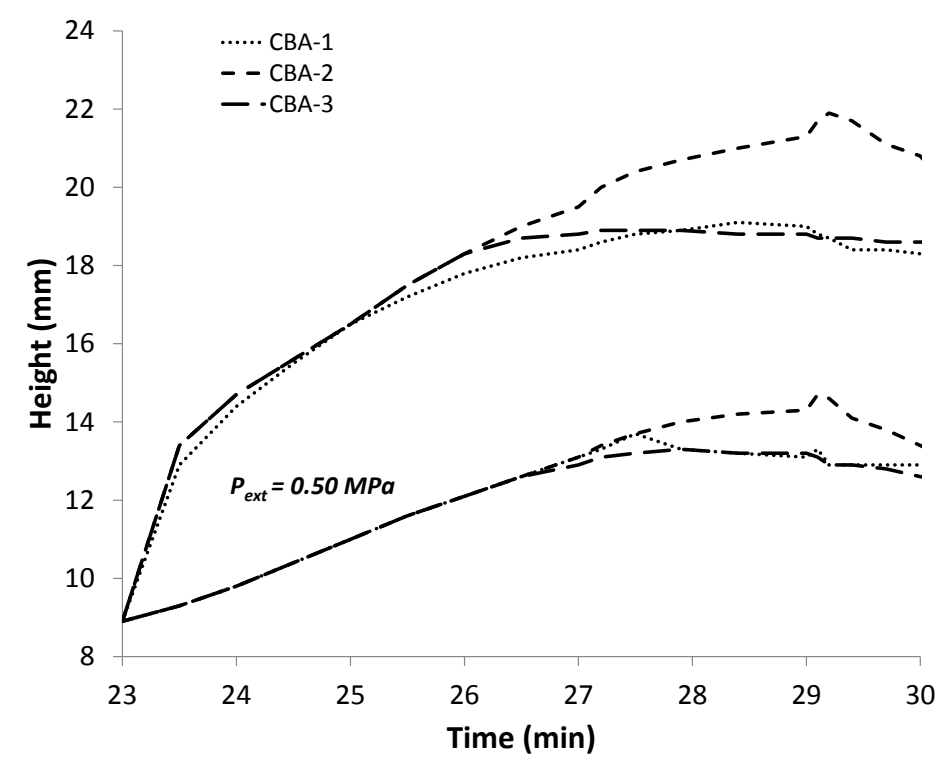

Figure 9-Evolution of the height of each sample during the expansion process

All samples show a remarkable volume expansion due to the gas creation and the foaming process. The expansion process takes about 4 minutes for CBA-818 and CBA-848, and 6 minutes for CBA-828, leading to expansion ratios around $200 \%$ with $P_{\text {ext }}=0.25 \mathrm{MPa}$ and $140 \%$ with $P_{\text {ext }}=0.5 \mathrm{MPa}$. After that time, the sample height reduces because of cooling and thermal shrinkage. The samples foamed with the CBA-828 showed a higher expansion than samples foamed with the other two CBAs. This may be explained by the larger number of moles of gas generated by the chemical reactions, as shown on figure 3. At the end of the process, shrinkage is clearly seen, especially in samples foamed with CBA-828. No shrinkage was observed in the lateral direction. For CBA-828 at $0.25 \mathrm{MPa}$, height reduces from $22.1 \mathrm{~mm}$ at $200 \mathrm{~s}$ to $20.1 \mathrm{~mm}$ at $260 \mathrm{~s}$, which corresponds to a volume reduction of 10 $\%$. For the same CBA at $0.5 \mathrm{MPa}$, the height reduction begins at $170 \mathrm{~s}$ with a maximum value of 14.8 $\mathrm{mm}$ and a final value of $13.3 \mathrm{~mm}$ at the end of the experience, with a similar volume reduction value.

The final volume $V_{f}$ and the expansion ratio after cooling are presented in table 3 , as well as the density $\rho$, calculated from the ratio between the mass and the volume of the expanded sample.

\begin{tabular}{|c|c|c|c|c|}
\hline Sample & $C B A$ & $\begin{array}{c}\boldsymbol{V}_{\boldsymbol{f}} \\
\left(\mathrm{cm}^{3}\right)\end{array}$ & Expansion ratio & $\begin{array}{c}\boldsymbol{\rho} \\
\left(\mathrm{g} / \mathrm{cm}^{3}\right)\end{array}$ \\
\hline $1-1$ & 1 & 5.62 & 1.94 & 0.47 \\
\hline $1-2$ & 1 & 3.98 & 1.38 & 0.65 \\
\hline $2-1$ & 2 & 6.31 & 2.18 & 0.41 \\
\hline $2-2$ & 2 & 4.17 & 1.44 & 0.63 \\
\hline $3-1$ & 3 & 5.84 & 2.02 & 0.45 \\
\hline $3-2$ & 3 & 3.92 & 1.36 & 0.66 \\
\hline
\end{tabular}

Table 3 - Final volume, expansion ratio and final density of foamed samples 
It is important to estimate the volume of gas retained in the sample to analyze possible gas diffusion outside the polymer. Assuming that the decomposition reaction is complete, the theoretical total volume of gas $V_{\text {gas }}^{\text {generated }}$ can be calculated from perfect gas equation.

$$
V_{\text {gas }}^{\text {generated }}=\frac{n(t)^{\text {total }} \cdot R \cdot T}{P_{\text {ext }}}
$$

$P_{\text {ext }}$ is the external pressure (MPa), $T$ is the foaming temperature, which is taken as a constant value of $210^{\circ} \mathrm{C}(483 \mathrm{~K})$ in a first approximation, and $R$ is the gas constant $\left(8.31 \mathrm{~J} \cdot \mathrm{mol}^{-1} \cdot \mathrm{K}^{-1}\right)$. The value of $n(t)^{\text {total }}$ corresponds to the total number of moles of gas created in the solid sample for the different CBAs at the end of the reaction.

According to figure 3, the total number of moles of gas created per gram of CBA are $0.0092 \mathrm{~mol} / \mathrm{g}$ in the case of the CBA-828 and CBA-848, and $0.0135 \mathrm{~mol} / \mathrm{g}$ in the case of the CBA-818. The total number of moles of gas generated in the sample $n(t)^{\text {total }}$ can be calculated by multiplying the previous values and the mass of CBA particles in each sample, in our case $2 \mathrm{wt}$. \% of $2.5 \mathrm{~g}$, and assuming that only the $70 \%$ of each CBA particle contains reactive elements.

The volume of gas generated for each CBA at each external pressure, deduced from equation (9), is shown on table 4 . This volume corresponds to the gas volume generated at the end of the expansion, before any cooling and thermal shrinkage of the polymer.

\begin{tabular}{|c|c|c|c|c|}
\hline Sample & CBA & $\begin{array}{c}P_{\text {ext }} \\
\text { (MPa) }\end{array}$ & $\begin{array}{l}n\left(t^{\text {total }}\right. \\
(\mathrm{mol})\end{array}$ & $\begin{array}{c}V_{\text {gas }} \text { generated } \\
\left(\mathrm{cm}^{3}\right)\end{array}$ \\
\hline $1-1$ & 1 & \multirow{3}{*}{0.25} & $3.22 \cdot 10^{-4}$ & 5.17 \\
\hline $2-1$ & 2 & & $4.72 \cdot 10^{-4}$ & 7.58 \\
\hline $3-1$ & 3 & & $3.22 \cdot 10^{-4}$ & 5.17 \\
\hline $1-2$ & 1 & \multirow{3}{*}{0.5} & $3.22 \cdot 10^{-4}$ & 2.58 \\
\hline $2-2$ & 2 & & $4.72 \cdot 10^{-4}$ & 3.79 \\
\hline $3-2$ & 3 & & $3.22 \cdot 10^{-4}$ & 2.58 \\
\hline
\end{tabular}

Table 4 - Theoretical total gas volume generated during the expansion processes for each sample, assuming that the decomposition reaction is complete

The fraction of gas in the foamed polymer can be also determined from image analysis. Several optical micrographs of the fracture surface of the expanded samples are presented in figure 10 . The structure is homogenous throughout the whole sample volume, which indicates that the thermal gradients do not influence the final foamed structure, even when the heating ramp may be locally different in the sample. 

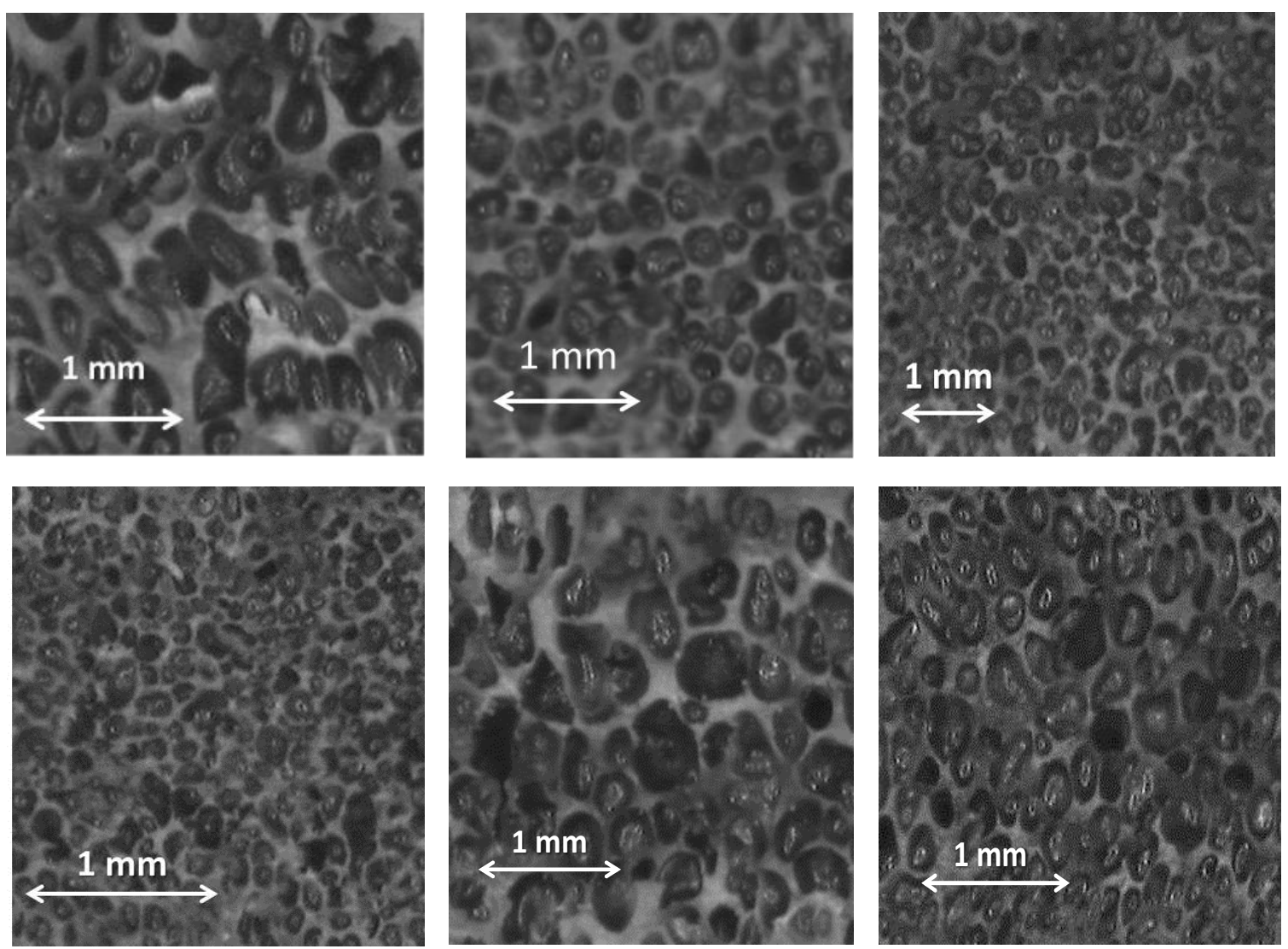

Figure 10 -Optical micrographs of the expanded samples
a) Sample 1-1
b) Sample 1-2 c) Sample 2-1
d) Sample 2-2
e) Sample 3-1 f) Sample 3-2

For a given CBA, increasing the pressure leads to a decrease of the bubble size, except for CBA-828, in which the bubble size remains almost the same. Figure 10 shows that $\mathrm{CBA}-828$, containing citric acid as reactive element, induces a finer bubble size and higher expansion rate than the other CBAs. The addition of sodium bicarbonate (CBA-818) or CBA based only on sodium bicarbonate (CBA 848), do not add any remarkable improvement concerning the foaming behavior, in terms of reducing bubble size, as compared to CBA-828.

Using the Image ${ }^{\circledR}$ software previously presented, it is possible to quantify the average bubble radius $R_{\text {bubble, }}$ the average distance between bubbles, (namely $\ell_{\text {bubble }}$ ), and the total volume of gas in each sample $V_{\text {gas }}$. As an example, figure 11 presents the histogram of both bubble radius, assuming that each bubble can be considered as a sphere (figure 11a), and the distance between bubbles (figure 11b). This parameter is calculated for each bubble, taking the minimum distance between the edge of this bubble and the surroundings ones. Results presented have been calculated from test 1-1, but similar calculations have been performed for the other samples. 

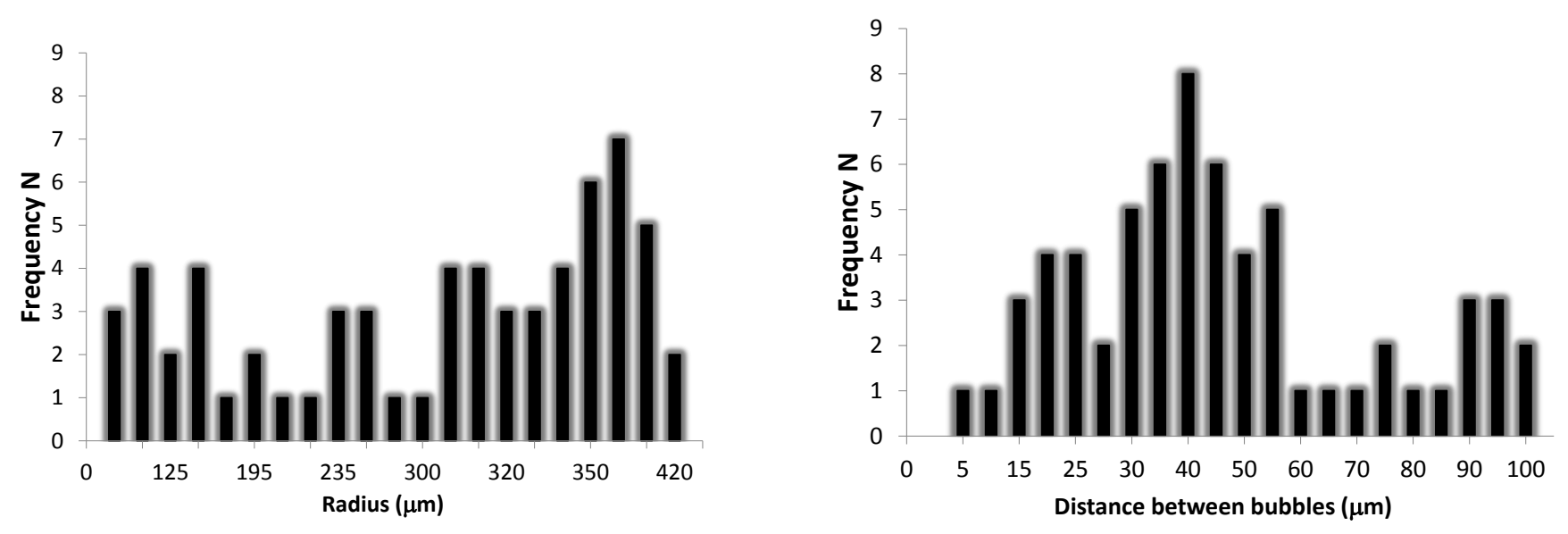

Figure 11 - Resulting histograms of the SEM micrograph presented in figure $10 a$

\section{a) Bubble radius b) Distance between bubbles}

The average results are obtained from 10 micrographs of each sample with a maximum error of \pm 5 $\%$.The software accounts for the number of bubble in each image and the average radius. The total cell number $N_{c}$ in the sample was calculated using equation (10) [26], which accounts for the 3D extrapolation starting from a $2 \mathrm{D}$ image:

$$
N_{C}=\frac{6\left(1-\frac{\rho_{F}}{\rho_{P}}\right)}{\pi R^{3}} V_{f}
$$

$\rho_{F}$ represents the foam density, and $\rho_{P}$ the solid polymer density $\left(0.91 \mathrm{~g} / \mathrm{cm}^{3}\right) . V_{f}$ represents the final volume of the sample after shrinkage. The experimental gas volume can be also easily calculated from expansion measurements, following the next equation:

$$
V_{\text {gas }}^{\text {direct }}=V_{f}-V_{i}
$$

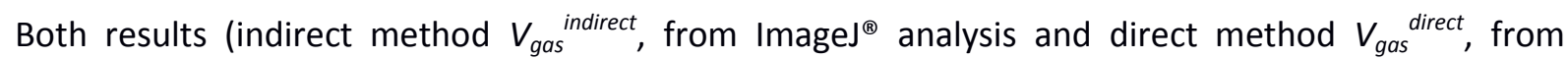
expansion measurements), together with the morphological determinations, are presented in table 5. They are in the same range, and the slight differences between both measurements can be due to specific errors associated to the software employed to analyze the optical micrographs. The last column of table $5, V_{\text {gas }}$ remaining , represents the total theoretical volume of gas generated. It is assumed than after cooling and shrinkage $\mathrm{H}_{2} \mathrm{O}$ condensates into liquid water, so it is necessary to extract the volume of water vapor generated from the total volume of gas generated calculated in table 4 . From the chemical reactions (1) (2) and (3) both citric acid and sodium bicarbonate decompose in one mole of $\mathrm{H}_{2} \mathrm{O}$ and one mole of $\mathrm{CO}_{2}$. The ratio between the molar masses of both components is $18 /(18+48)=0.27$, indicating that the $27 \%$ of the gas generated transforms into liquid water by condensation.

The proportion between the measured gas volume and the theoretical gas volume varies between $50 \%$ and $75 \%$. 


\begin{tabular}{|c|c|c|c|c|c|c|c|c|c|c|}
\hline Test & CBA & $\begin{array}{c}\text { Bubble } \\
\text { count }\end{array}$ & $\begin{array}{c}R_{\text {bubble }} \\
(\boldsymbol{\mu m})\end{array}$ & $\begin{array}{c}\boldsymbol{V}_{\text {bubble }} \\
\left(\mathbf{m m}^{3}\right)\end{array}$ & $\begin{array}{c}L_{\text {bubble }} \\
(\boldsymbol{\mu m})\end{array}$ & $\begin{array}{c}\rho_{\boldsymbol{F}} \\
\left(\mathbf{g} / \mathbf{c m}^{3}\right)\end{array}$ & $\begin{array}{c}\mathbf{N}_{\boldsymbol{c}} \\
\left(\mathbf{c m}^{-3}\right)\end{array}$ & $\begin{array}{c}\boldsymbol{V}_{\text {gas }}^{\text {indirect }} \\
\left(\mathbf{c m}^{3}\right)\end{array}$ & $\begin{array}{c}\boldsymbol{V}_{\text {gas }}^{\text {direct }} \\
\left(\mathbf{c m}^{3}\right)\end{array}$ & $\begin{array}{c}\boldsymbol{V}_{\text {gas }}^{\text {remaining }} \\
\left(\mathbf{c m}^{3}\right)\end{array}$ \\
\hline $1-1$ & 1 & 64 & 360 & 0.195 & 50 & 0.47 & $1.43 \cdot 10^{4}$ & 2.89 & 2.73 & 3.77 \\
\hline $1-2$ & 1 & 108 & 170 & 0.021 & 42 & 0.65 & $8.97 \cdot 10^{4}$ & 1.19 & 1.09 & 1.88 \\
\hline $2-1$ & 2 & 241 & 120 & 0.007 & 25 & 0.41 & $4.30 \cdot 10^{5}$ & 3.11 & 3.42 & 5.53 \\
\hline $2-2$ & 2 & 292 & 85 & 0.003 & 23 & 0.63 & $7.58 \cdot 10^{5}$ & 1.35 & 1.28 & 2.76 \\
\hline $3-1$ & 3 & 79 & 350 & 0.180 & 56 & 0.45 & $1.65 \cdot 10^{4}$ & 2.90 & 2.95 & 3.77 \\
\hline $3-2$ & 3 & 121 & 190 & 0.029 & 38 & 0.66 & $6.24 \cdot 10^{4}$ & 1.19 & 1.03 & 1.88 \\
\hline
\end{tabular}

Table 5 - Gas volume and morphological parameters in the expanded samples

The order of magnitude of the thermal volume variation between $210{ }^{\circ} \mathrm{C}$ and room temperature for the polypropylene is around $20 \%$. This cannot explain the measured difference. An incomplete chemical reaction is unlikely according to the DSC and TGA measurements. It could be speculated that a part of the gas generated has not been nucleated and does not produce any expansion. It could remain dissolved in the polymer matrix or have diffused outside the sample during the expansion process. To test these hypotheses, the foamed samples were re-heated up to $210^{\circ} \mathrm{C}$ to analyze a possible second expansion produced by the remaining dissolved gas, with negative results. This indicates that the gas has probably diffused out of the samples. The gas diffusion outside the sample has been observed in HR-SEM micrographs, which shows the presence of micro channels in the sample surface (figure 12).

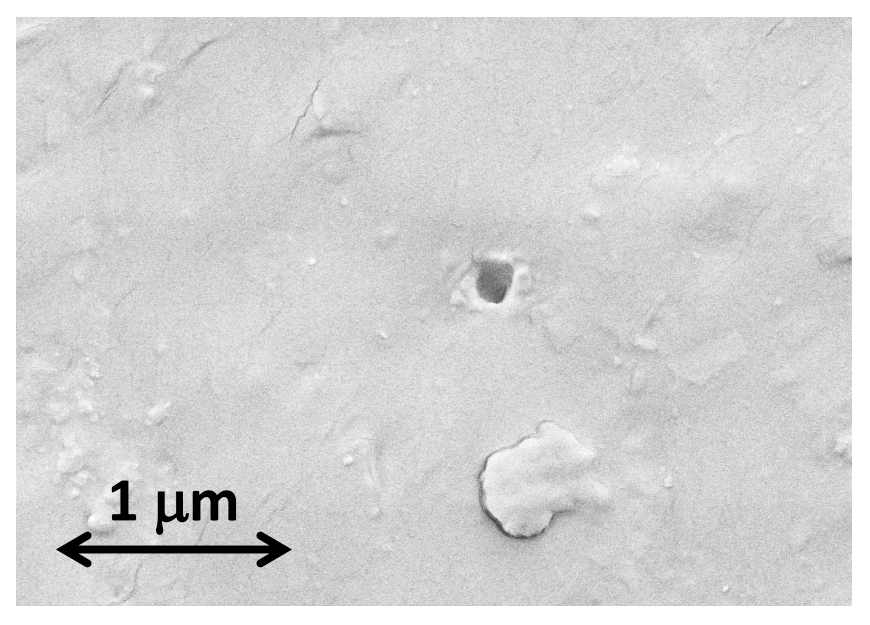

Figure 12 - Micro channel in the surface of the foamed sample

Another interesting parameter that can be analyzed from the foaming experiment is the coalescence. It is possible to define the ratio $k$ between the final number of cells $N_{c}$ and the initial number of reactive agent particles $N_{p}$. It lies between $0.2 \%$ and $12 \%$, indicating that coalescence is a very important phenomenon that will be discussed lately.

\section{3 - Theoretical approach}

Many studies have been devoted to the development of numerical models for the bubble nucleation and growth in polymeric foaming process. In the classical work presented by Amon and Denson [27] a complete mathematical analysis of a bubble growth in a Newtonian matrix is presented. Bikard et al [28] and Bruchon [29] solved the same problem with a 3D finite element method which allows accounting for the simultaneous growing of multiple bubbles. Koopmans et al [30] introduced a 
viscoelastic multimode Maxwell behavior for the polymer matrix in a "bubble influence volume" surrounding the growing bubble. They also account for non-isothermal phenomena occurring at die exit in an extrusion process. Otsuki and Kanai [31] introduced a more realistic Phan-Tien Tanner viscoelastic constitutive equation which limits the dramatic increase of the elongational viscosity in the Maxwell model. Shafi et al [32, 33] and Joshi et al [34] developed a homogeneous nucleation model that they coupled to the Newtonian Amon and Denson bubble growing model. Taki $[35,36]$ compared these calculation results to experiments performed under several pressure release rates. Feng and Bertelo [37] investigated bubble nucleation in a viscoelastic polymer melt (Oldroyd B constitutive equation) containing nucleating agents.

All these works assume that the polymer is saturated with gas and that this gas diffuses from the matrix to the bubble. In our case, the diffusion process is in the opposite direction from the bubble, which is nucleated around the CBA particle, towards the polymer matrix. Recently Emami et al [38] analyzed the bubble nucleation in non-pressurized foaming CBA systems starting from solid materials, composed of PP and CBA powders as in our experiments. It was observed that the nucleation process proceeded in two distinct stages, namely primary and secondary nucleation. Primary nucleation occurred in the interstitial regions of the sintered plastic powder and the agglomerated blowing agent particles acted as nucleation sites, and secondary nucleation occurs in the polymer melt. The visual observations indicated that most of the first generation of bubbles endured the entire foaming process, whereas most of the bubbles generated during secondary nucleation disappeared over time. These results support the previous assumption which considers each reactive agent particle as a nucleation site, with no further nucleation phenomenon.

In the following, a kinetic model for a single bubble expansion in a Newtonian fluid coupled with the gas diffusion in the surrounding polymer matrix is proposed. The nucleation phenomenon will be simplified, assuming that each reactive agent particle can be considered as a nucleation site. The model has been applied to the experimental conditions presented in the previous section. The sensitivity of the model to several unknown parameters has been tested. Comparison between calculation and experiments will be discussed.

\section{1 - Single bubble growth model}

A schematic of the bubble growth model is shown in figure 13. A reactive agent particle creates $n(t)_{\text {created }}$ moles of gas by the chemical decomposition reaction-deduced from the TGA curve. The bubble growth is governed by the competition between the gas which remains within the bubble and induces the growing mechanism (number of moles $n(t)$ ) and the moles of gas $n(t)_{\text {diffused }}$ which diffuses in the surrounding polymer matrix at the external pressure $P_{\text {ext }}$. The gas concentration $C(r, t)$ propagates concentrically in the surrounding polymer melt. The average concentration of gas at the bubble surface, $\left.C(r, t)\right|_{r=R}$, is related to the gas pressure inside the bubble $P_{\text {gas }}$ through the solubility factor $K$. 


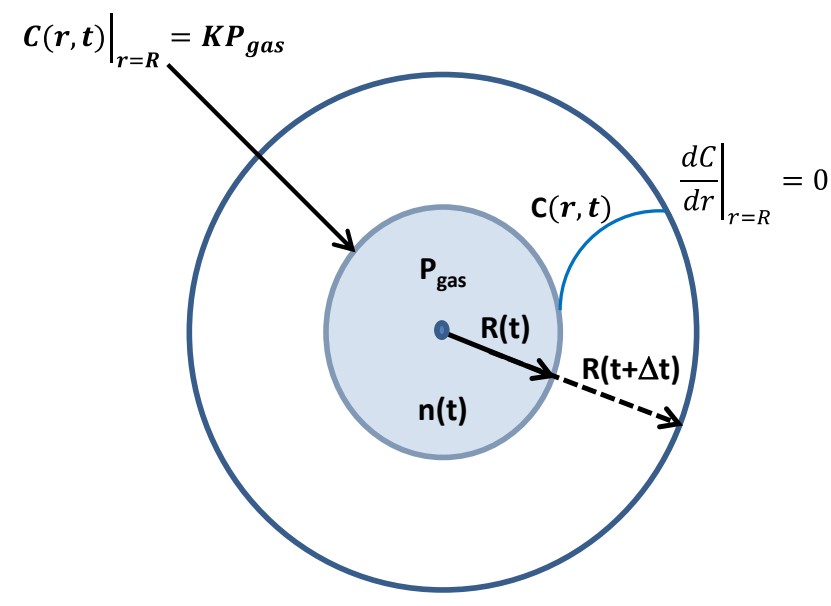

Figure 13 - Single bubble growth model

The following assumptions are made:

1 - The bubble is spherically symmetric when it nucleates and remains so for the entire period of growth.

2 - The polymer matrix is Newtonian.

3 - The growth process is considered isothermal. Latent heat of reaction is neglected.

4 - Inertia effects are neglected and the fluid is assumed to be incompressible, which is reasonable in the pressure range studied.

5 - The gas released by the chemical reactions follows the ideal gas law.

6- The matrix is considered as an infinite medium and one single bubble is considered. This condition will be commented later, in terms of the gas diffusion distances, bubble radius and sample dimensions.

The first step consists in the determination of the number of moles of created gas $n(t)_{\text {created }}$. Three different $C B A$ kinetics are shown in figure 3. Considering the experimental foaming results, two different CBAs, CBA-818 and CBA-848, present similar results in terms of expansion rate and morphology. This indicates that the coupling reaction between citric acid and sodium bicarbonate has not occurred at the foaming temperature of the experience $\left(210{ }^{\circ} \mathrm{C}\right)$, as indicated in the DSC curves figure 2. For this reason, two different numerical calculations results will be presented, first for the PP + CBA-828 samples (2-1 and 2-2) with the decomposition of citric acid, and then for the PP + CBA-848 samples (3-1 and 3-2) with the sodium bicarbonate decomposition reaction.

Figure 14 presents the theoretical fitting of the experimental TGA data extrapolated to one single particle of reactive agent for both decomposition reactions, at a temperature of $210{ }^{\circ} \mathrm{C}$. The low heating rate (about $6{ }^{\circ} \mathrm{C} / \mathrm{min}$ according to the temperature measurements during the foaming experiment), permits, as a first approximation, the extrapolation of the non-isothermal results derived from the TGA to isothermal kinetics at $210^{\circ} \mathrm{C}$. The total reaction time was about $100 \mathrm{~s}$, much lower than the foaming time employed during the expansion experiment, which assures that the chemical reactions are complete. Different kinetic models can be found in the literature, such as the 
Kamal and Sourour model [39]. In our case, the best fitting correlation was found using Boltzmann's exponential functions:

$$
n_{\text {created }}(t)=A_{2}+\frac{A_{1}-A_{2}}{1+\exp \left(\frac{t-t_{0}}{\lambda}\right)}
$$

Fitting parameters, as well as the quality of the correlation are presented in table 6.
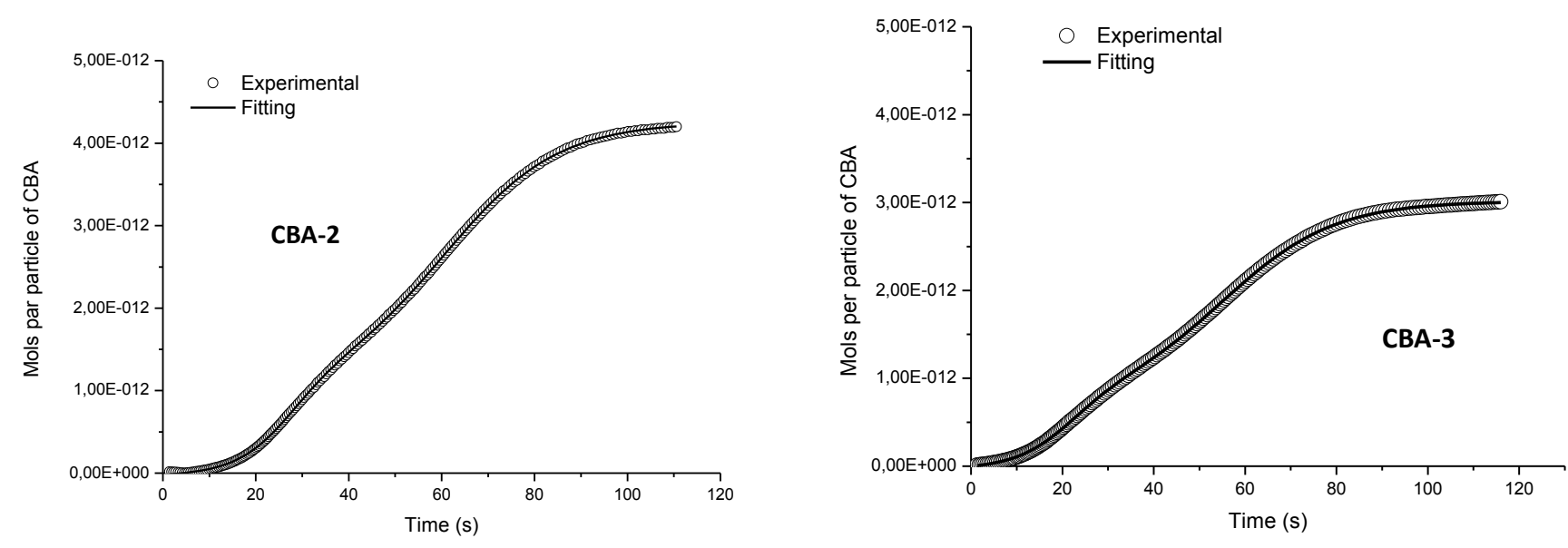

Figure 14 - Theoretical fitting of the number of moles created during the CBA decomposition

a) $C B A-828$ b) $C B A-848$

\begin{tabular}{|c|c|c|c|c|c|}
\hline $\mathbf{C B A}$ & $\boldsymbol{A}_{\mathbf{1}}(\mathbf{m o l})$ & $\boldsymbol{A}_{\mathbf{2}}(\mathbf{m o l})$ & $\boldsymbol{t}_{\boldsymbol{0}}(\mathbf{s})$ & $\lambda(\boldsymbol{s})$ & $\boldsymbol{R}^{\mathbf{2}}$ \\
\hline 2 & $4.17 \cdot 10^{-13}$ & $2.95 \cdot 10^{-14}$ & 63.12 & 8.59 & 0.9991 \\
\hline 3 & $3.92 \cdot 10^{-13}$ & $2.18 \cdot 10^{-14}$ & 57.87 & 9.20 & 0.9994 \\
\hline
\end{tabular}

Table 6 - Fitting parameters of the number of moles of gas created during the decomposition reaction of the CBAs.

The ordinary differential equation for the bubble radius growth as a function of time writes [35]:

$$
\frac{d R}{d t}=\frac{R}{4 \eta}\left(\frac{n(t) \Re T_{g}}{\frac{4}{3} \pi R^{3}}-P_{\text {ext }}-\frac{2 \gamma}{R}\right)
$$

$R$ is the bubble radius, $\eta$ is the polymer viscosity and $\gamma$ is the surface tension. As explained before, the gas temperature $T_{g}$ is assumed to be constant $\left(210^{\circ} \mathrm{C}\right)$ during the expansion process.

The variation of the number of moles of gas $n(t)$ inside the bubble is derived from equation 14 :

$$
\frac{d n}{d t}=\frac{d n(t)_{\text {created }}}{d t}-\frac{d n(t)_{\text {diffused }}}{d t}
$$


The number of moles of gas which diffuse outside the bubble in the surrounding polymer matrix is obtained from the mass transfer of CBA at the gas-polymer interface and it can be expressed as follows:

$$
\frac{d n(t)_{\text {diffused }}}{d t}=-\left.4 \pi R^{2} D \frac{\partial C}{\partial r}\right|_{r=R}
$$

$D$ is the diffusion coefficient, and $C$ is the gas concentration of the diffused gas. The concentration profile is given by a diffusion equation around the bubble which writes:

$$
\frac{d C}{d t}=\frac{\partial C}{\partial t}+u(r, t) \frac{\partial C}{\partial r}=\frac{D(T)}{r^{2}} \frac{\partial}{\partial r}\left(r^{2} \frac{\partial C}{\partial r}\right)
$$

$u$ is the velocity field related to the bubble expansion, in spherical coordinates. The ratio between the convection term and the diffusion term is a Peclet number given by (see Joshi et al [34]):

$$
\frac{\text { convection }}{\text { diffusion }} \approx \frac{u / R}{D / R^{2}}
$$

The diffusion coefficient value can be taken from the literature [35], with a typical value, for PP and $\mathrm{PE} / \mathrm{CO}_{2}$ systems, of $D=10^{-8} \mathrm{~m}^{2} / \mathrm{s}$. The calculation without diffusion will show that the bubble radius goes from $5.10^{-6}$ to $2.10^{-4} \mathrm{~m}$ and the growth speed of the bubble radius is around $10^{-6} \mathrm{~m} / \mathrm{s}$. Therefore, convection can be neglected.

The numerical implementation requires defining boundary and initial conditions. Three physical parameters must be defined at time $t=0$. First, the average size of the reactive agent particles can be considered as the initial bubble radius $R_{0}$, as a first approximation. This assumption is only an approximation, and the sensitivity of the calculations when changing the initial radius will be analyzed. The initial number of moles of gas $n_{0}$ can be directly calculated from the gas perfect law using the initial radius $R_{0}=R=4.46 \mu \mathrm{m}$, at the two different external pressures $0.25 \mathrm{MPa}$ and 0.5 $\mathrm{MPa}$. The boundary condition for the gas concentration at the bubble surface $C(R, t)$ is described by Henry's law:

$$
C(R, t)=\frac{3}{4} k \frac{n(t) \Re T_{g}}{\pi R^{3}}
$$

\section{2 - Numerical implementation}

The numerical implementation of the previous equations is carried out by means of an incremental time marching approach during the decomposition reaction time (about $100 \mathrm{~s}$, see figure 14). This approximation implies that the expansion process is limited to the decomposition reaction time, and that no further expansion occurs later. The variation of the number of moles of gas created is obtained by differentiating equation 12 : 


$$
\frac{d n(t)_{\text {created }}}{d t}=-\frac{1}{\lambda} \cdot \frac{\left(A_{1}-A_{2}\right) \cdot \exp \left(\frac{t-t_{0}}{\lambda}\right)}{\left(1+\exp \left(\frac{t-t_{0}}{\lambda}\right)\right)^{2}}
$$

250 iterations were employed to solve the equations. We adjust the time step $\Delta \mathrm{t}$ in order to obtain an incremental radius variation less than $1 \%$ :

\section{3 - Results and discussion}

Table 7 presents the physical parameters and the initial conditions employed in the foaming simulation.

\begin{tabular}{|c|c|c|c|}
\hline Parameter & CBA 2 & CBA 3 & Units \\
\hline Initial number of moles $n_{0}$ & $(3.56$ or 7.13$) \cdot 10^{-14}$ & $(3.56$ or 7.13$) \cdot 10^{-14}$ & $\mathrm{~mol}$ \\
\hline Initial radius $R_{0}$ & $4.46 \cdot 10^{-6}$ & $4.46 \cdot 10^{-6}$ & $\mathrm{~m}$ \\
\hline Viscosity $\eta$ & 500 & 500 & $\mathrm{~Pa} \cdot \mathrm{s}$ \\
\hline Surface tension $\gamma^{*}$ & 0.020 & 0.020 & $\mathrm{~J} \cdot \mathrm{m}^{-2}$ \\
\hline Diffusion coefficient $D^{*}$ & $8 \cdot 10^{-9}$ & $8 \cdot 10^{-9}$ & $\mathrm{~m}^{2} \cdot \mathrm{s}^{-1}$ \\
\hline Gas constant $R$ & 8.314 & 8.314 & $\mathrm{~m}^{3} \cdot \mathrm{Pa}^{-1} \cdot \mathrm{Kol}^{-1}$ \\
\hline Gas temperature $T_{g}$ & 483 & 483 & $\mathrm{~K}$ \\
\hline External pressure $P_{\text {ext }}$ & $(2.5$ or 5$) \cdot 10^{5}$ & $(2.5$ or 5$) \cdot 10^{5}$ & $\mathrm{~Pa}$ \\
\hline Solubility parameter $K^{*}$ & $1.15 \cdot 10^{-4}$ & $1.15 \cdot 10^{-4}$ & $\mathrm{~mol} \cdot \mathrm{m}^{-3} \cdot \mathrm{Pa}^{-1}$ \\
\hline
\end{tabular}

Table 7 - Physical parameters and initial conditions employed for the foaming simulation

*Values taken from literature [35]

Figure 15 presents the gas diffusion profiles outside the bubble for five different reaction times and both CBAs and an external pressure of $0.25 \mathrm{MPa}$. Results for the diffusion profiles taking an external pressure of $0.5 \mathrm{MPa}$ were almost equivalent, which indicates that the slight variation in the external pressure does not affect significantly the gas diffusion.
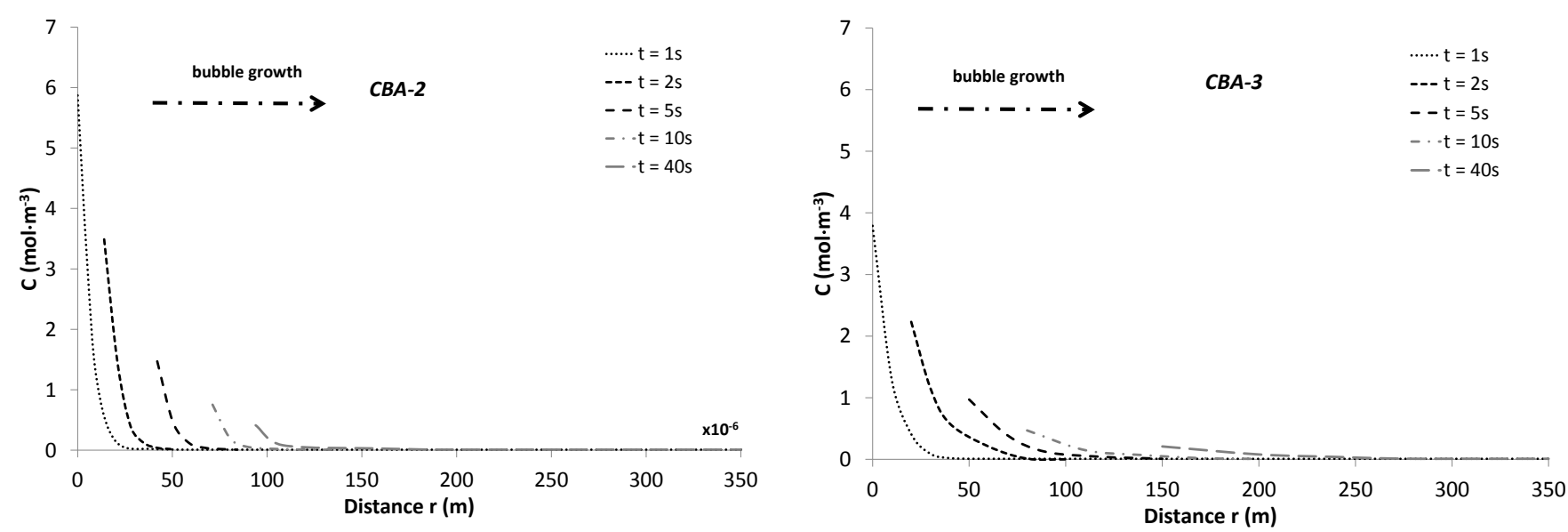

Figure 15 - Gas diffusion profiles obtained from the diffusion equation

a) $C B A-828$ b) $C B A-848$ 
The quantity of gas which diffuses outside the bubble increases as the reaction develops. For reaction times close to $40 \mathrm{~s}$, the gas diffusion penetration thickness is around $150 \mu \mathrm{m}$ for the CBA828 , and $300 \mu \mathrm{m}$ for the CBA-848, whereas for reaction times of $2 \mathrm{~s}$, these distances are only $50 \mu \mathrm{m}$ and $80 \mu \mathrm{m}$, respectively. The gas concentration at the gas-polymer interphase decreases strongly with time, even when the quantity of gas generated inside the bubble $n(t)$ increases according to the TGA kinetics. The reason for this decrease is related to the dependence of $C(R, t)$ with bubble radius in a proportion $C \propto R^{-3}$ (see equation 18 ). At high reaction times, the gas concentration at the interphase is negligible. The initial concentration values $C(R, t)$ are higher for the CBA-828 due to the higher quantity of moles of gas generated by the citric acid decomposition.

Figure 16 compares the number of moles of gas created by the decomposition reaction, diffused and retained in the bubble during the expansion process for an external pressure of $0.5 \mathrm{MPa}$.
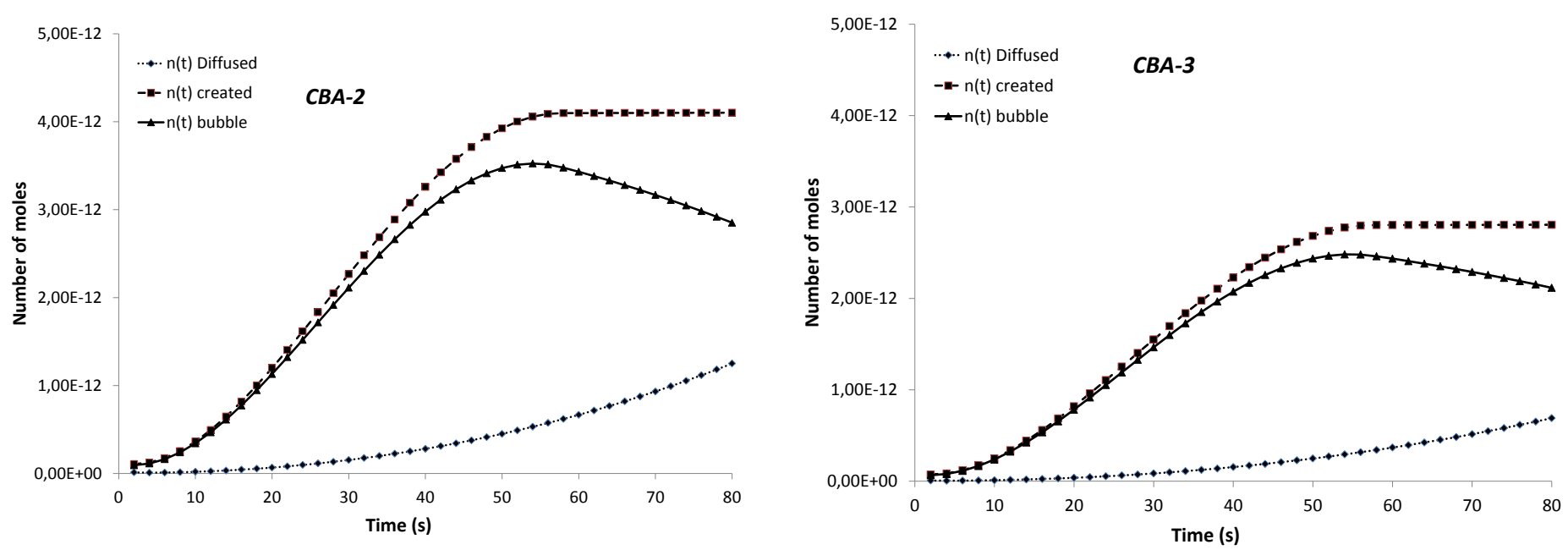

Figure 16 -Evolution of the number of moles of gas during the foaming expansion of a single bubble
a) CBA 828
b) $C B A 848$

These results show that, in the foaming conditions of figure 16, the diffusion process becomes noticeable from $20 \mathrm{~s}$ for both CBAs. From that time, the quantity of diffused gas increases, reaching a final value about $1.35 \cdot 10^{-12}$ moles for the CBA-828 and a value about $7 \cdot 10^{-13}$ for the CBA-848. It can be seen also that at the end of the chemical reaction of CBA-828, the quantity of gas diffused is higher than the gas inside the bubble*. On the other hand, the number of moles of gas created by the decomposition reaction reaches a value between $4 \cdot 10^{-12}$ moles and $2.7 \cdot 10^{-12}$ moles, for the CBA828 and CBA-848, respectively. These differences between both CBAs can be related to the kinetics of the decomposition reactions, which shows that the quantity of gas created by the CBA- 848 is slightly higher than the quantity created by the CBA-828.

At the end of the reactions, the ratios between diffused and created gas are about $33 \%$ and $28 \%$ for CBA-828 and CBA-848 respectively. These values are in reasonable agreement with the experimental values found previously in table 5 (between $25 \%$ and $50 \%$ of diffused gas).

Figure 17 presents the predicted radius evolution for both CBA-828 and CBA-848. Two different situations are presented. In the first case, diffusion is not considered, and the number of moles of gas $n(t)$ are taken directly from the TGA measurements. In the second case, the gas diffusion process is considered, and $n(t)$ is obtained from the data of figure 16 . 

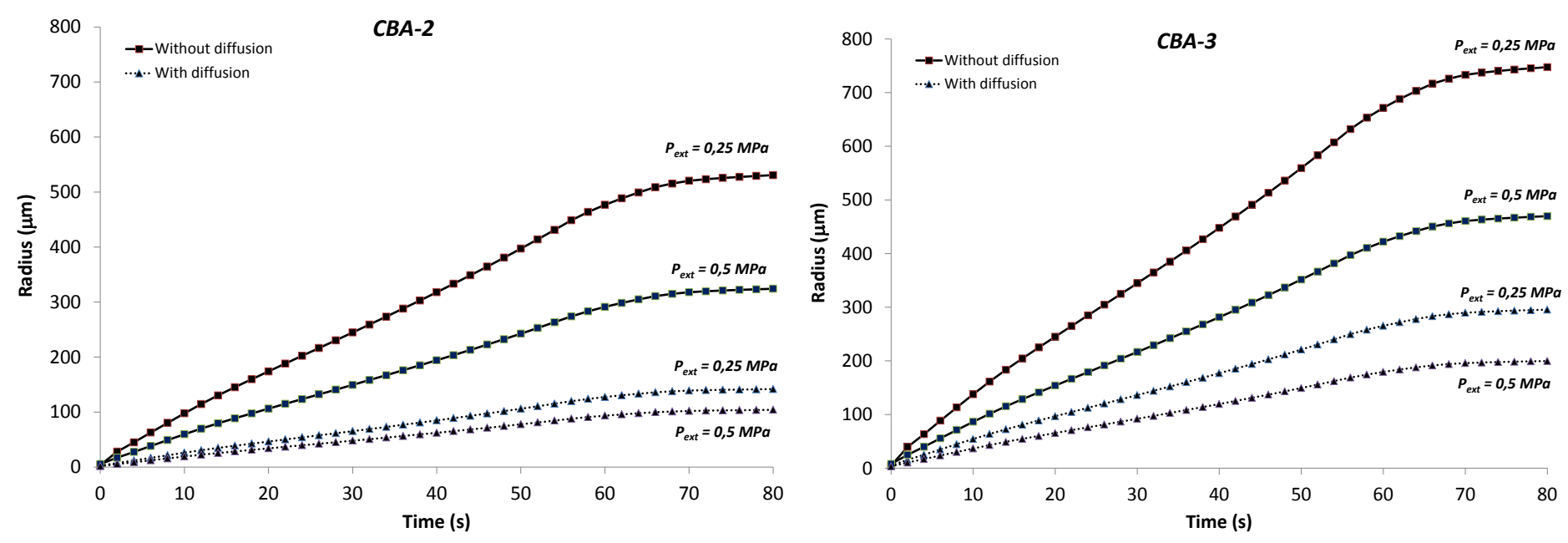

Figure 17-Numerical prediction of the single bubble growth during the expansion process

\section{$\begin{array}{ll}\text { a) } C B A 828 & \text { b) } C B A 848\end{array}$}

The final bubble radius depends strongly on the external pressure and is obviously limited by the gas diffusion. For the CBA-828 (figure 17a), when the external pressure is $0.25 \mathrm{MPa}$, the bubble radius reaches $530 \mu \mathrm{m}$ when gas diffusion is neglected, and about $130 \mu \mathrm{m}$ when the diffusion process is considered. When the external pressure is increased up to $0.5 \mathrm{MPa}$, these values are $330 \mu \mathrm{m}$ and 90 $\mu \mathrm{m}$ respectively. The theoretical values obtained (considering the diffusion process), are in qualitative agreement with the foaming experiments values $(120 \mu \mathrm{m}$ and $85 \mu \mathrm{m}$ respectively, see table 5). A similar analysis can be performed for the CBA-848 (figure 17b). In this case, the theoretical values obtained considering the diffusion process are about $300 \mu \mathrm{m}$ and $180 \mu \mathrm{m}$, for both external pressures of $0.25 \mathrm{MPa}$ and $0.5 \mathrm{MPa}$. These results are also in qualitative agreement with the foaming experiments ( $350 \mu \mathrm{m}$ and $190 \mu \mathrm{m}$ respectively, see table 5).

Using the expansion $R(t)$ value makes possible to compute the velocity value $u$ at the bubble/polymer interface. The evolution of $u$ for the CBA-828, considering only the results including the diffusion term, are presented in figure 18 (the results for the CBA-848 are similar). As it can be seen in figure $18, u$ values are around $10^{-6} \mathrm{~m} / \mathrm{s}$ which justifies neglecting the convection term in the diffusion equation (16) .

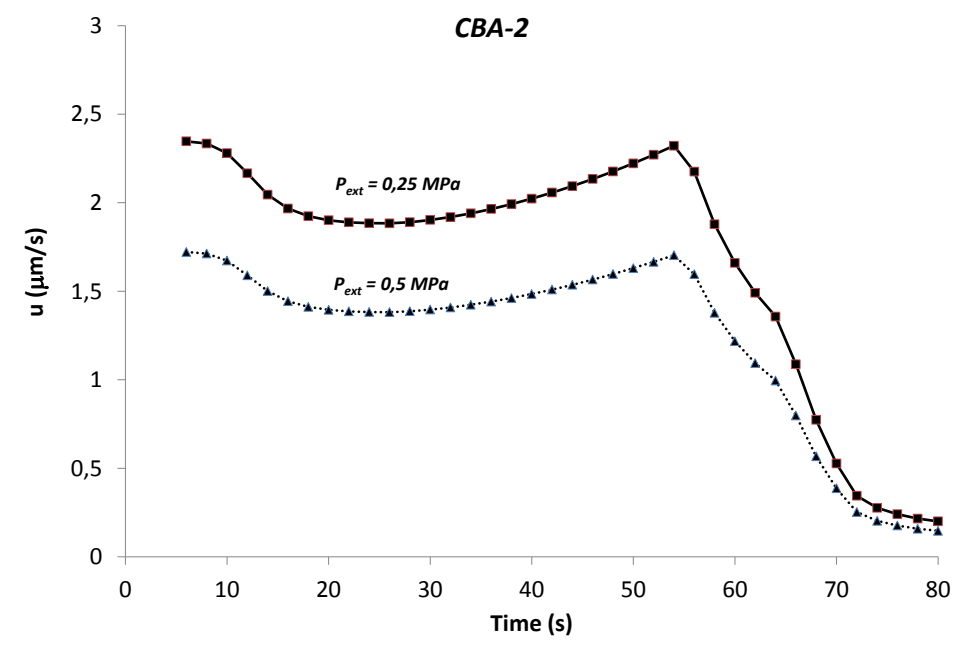

Figure 18 - Bubble growth speed ( $u$ ) during the expansion process (CBA-828) 
The sensitivity of the model to control parameters, especially the initial radius $R_{0}$, and physical parameters (the diffusion coefficient $D$ and the viscosity $\eta$ ) on the bubble growth rate has been investigated (figure 19). The results are shown for CBA-848 for an external pressure of $0.25 \mathrm{MPa}$.
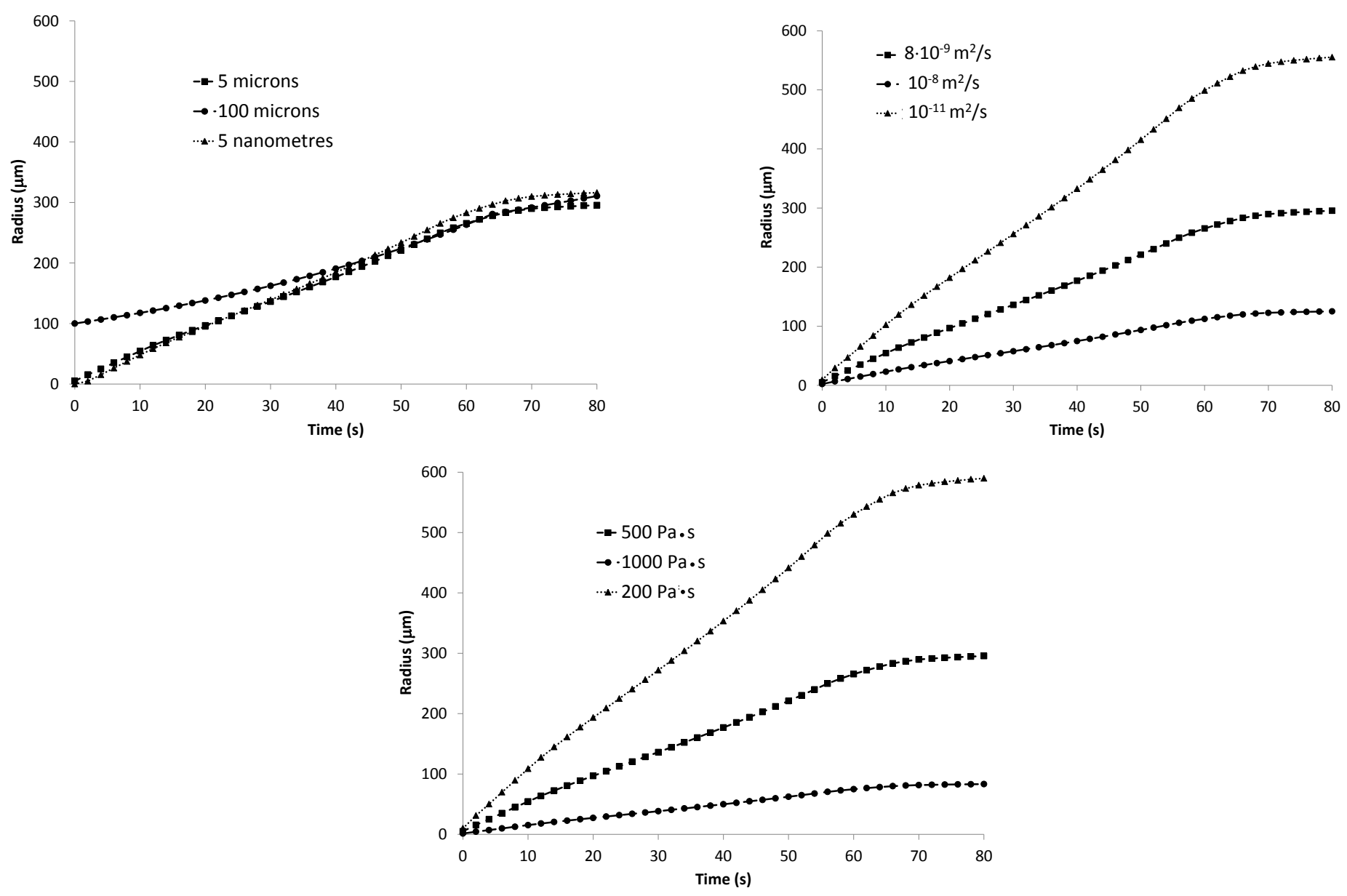

Figure 19-Influence of several parameters in the single bubble growth (Test 3-1)

\section{$\begin{array}{llll}\text { a) Initial radius } R_{0} & \text { b) Diffusion coefficient } D & \text { c) Viscosity } \eta\end{array}$}

In figure 19a, three different values of the initial radius $R_{0}$ were chosen $(5 \mathrm{~nm}, 5 \mu \mathrm{m}$ and $100 \mu \mathrm{m})$. The lowest value corresponds to the typical critical radius value that can be found in the literature for homogeneous nucleation [4]. The final predicted bubble radius is only slightly influenced by the initial radius value (between $290 \mu \mathrm{m}$ and $320 \mu \mathrm{m}$ ) but differences are obviously very important at intermediate time steps (till $30 \mathrm{~s}$ ).

Varying the diffusion coefficient from $10^{-8} \mathrm{~m}^{2} / \mathrm{s}$ to $10^{-11} \mathrm{~m}^{2} / \mathrm{s}$ leads to a final bubble radius around 100 $\mu \mathrm{m}$ and $600 \mu \mathrm{m}$, respectively (figure 19b). Typical diffusivity values for a gas-polymer system place in the rage between $10^{-8}-10^{-10} \mathrm{~m}^{2} / \mathrm{s}$. The chosen diffusivity value was taken directly from the literature [35], and corresponds to the diffusivity value of $\mathrm{CO}_{2}$ into a PP matrix at $483 \mathrm{~K}$. A more detailed analysis should include the diffusion process of water vapor into a PP matrix. It is possible to assume a value of the diffusion coefficient of water vapor slightly higher than the value for $\mathrm{CO}_{2}$ due to the lower molar mass. However, the range of diffusion coefficients analyzed in figure $19 \mathrm{~b}$ is expected to cover both $\mathrm{CO}_{2}$ and water vapor diffusion process. 
It can be observed that increasing viscosity $\eta$ from $200 \mathrm{~Pa} \cdot \mathrm{s}$ to $1000 \mathrm{~Pa} \cdot \mathrm{s}$ induces a decrease of the final bubble radius from $600 \mu \mathrm{m}$ to less than $100 \mu \mathrm{m}$ (figure 19c). The viscosity was determined experimentally from shear rheological measurements and presents a Newtonian plateau around 500 Pa.s at the strain rates encountered during the foaming process. During the foaming process, the flow around a single bubble is purely elongational, which means that the chosen viscosity value determined by shear measurements may be significantly underestimated. This justifies testing higher viscosity values in the single bubble growth model, as seen in figure $19 \mathrm{c}$.

The influence of the initial number of moles $n_{0}$ and the influence of the initial radius $R_{0}$ are correlated from the gas perfect law $\left(n_{0} \propto R_{0}^{3}\right)$.

Finally, as the number of bubbles is less important than the number of CBA particles and as the final radius of the bubbles is more important than the mean initial distance between the particles, it is clear that bubble coalescence appears quite early in the process. Due to the important CBA particle size distribution (figure 5), one can believe that the biggest initial particles will induce the biggest bubbles in the first stage of their development (see figure 19a), which will coalesce with the small surrounding bubbles initiated by the smallest initial particles. Considering, for example, one bubble with a diameter of $100 \mu \mathrm{m}$ surrounded by eight bubbles with a diameter of $25 \mu \mathrm{m}$ (see figure 19a at $\mathrm{t}=5 \mathrm{~s}$ ), the final diameter of the central bubble will be only $108 \mu \mathrm{m}$ after coalescence. As a consequence, if $88 \%$ of the bubbles disappear during the foaming process, (which corresponds to the scenario of one bubble surrounded by eight smaller bubbles), the final bubble diameter will be only enhanced by $8 \%$. This may explain the good agreement between the calculation result which does not account for coalescence and the experimental observation where coalescence takes place.

\section{4-Conclusion}

A simple polymer expansion experiment has been designed to test the foaming behavior of different chemical blowing agents (CBA), submitted to different pressure conditions. The bubble size and bubble size distribution depend on the blowing agent and on the applied pressure and careful bubble size measurements obtained by Image Analysis correlate well with the global macroscopic expansion of the foamed sample.

A single bubble expansion model assuming nucleation on each CBA particle, accounting for the different chemical reactions and for the gas diffusion from the bubble to the surrounding polymer matrix agrees fairly well with the experimental results, despite the strong hypothesis. This allows us to build a simple method to estimate the capability of a CBA to develop a foamed structure and the resulting mechanical properties.

Further studies analyzing injection molding experiments with the same CBAs are in progress. 


\section{References}

1. D. Li, T. Liu, L. Zhao, and W. Yuan. Ind. Eng. Chem. Res. 48, (2009).

2. M. Hasan, Y.G. Li, G. Li, C.B. Park, and P. Chen. J. Chem. Eng. Data., 55, (2010).

3. Z. Lei, H. Ohyabu, Y. Sato, H. Inomata, and R. Smith. J. of Supercritical Fluids, 40 (2007).

4. J.H. Han, and C.D. Han. J. of Polym. Sci. Part B, 28, (1990).

5. W. Zhai, J. Yu, L. Wu, W. Ma, and, J. He. Polymer, 47 (2006).

6. S. Areerat, E. Funami, Y. Hayata, D. Nakagawa, and M. Ohshima. Polym. Eng. Sci., 44, (2004).

7. A. Arefmanesh, S.G. Advani, and E.E. Michaelides. Inter. J. Heat Mass Transf., 35 (2004).

8. D.C. Venerus. Polym. Eng. Sci., 41, (2001).

9. D.C. Venerus. Cell. Polym., 22, (2003).

10. D.F. Baldwin, N.P. Suh and M. Shimbo. Cell. Polym., 36, 11 (1996).

11. C.B. Park and N.P. Suh. Polym. Eng. Sci. 26, 1 (1996).

12. C.B. Park, D.F. Baldwin and N.P.Suh. Polym. Eng. Sci. 35, 5 (1995).

13. X. Han, K.W. Koelling, D.L. Tomasko and L.J. Lee. Polym. Eng. Sci. 35, 11 (2002).

14. S. Wong, J.W.S. Lee, H.E. Naguib, and C.B. Park. Macromol. Mater. Eng., 293, (2008)

15. S-C. Chen, W-H. Liao; and R-D. Chien. Inter. Comm. Heat Mass Trans., 39, (2012).

16. A.K. Nema, A.V. Deshmukh, K. Palanivelu, S.K. Sharma, and T. Malik. J. Cell Plast., 44, (2008).

17. S. Nakai, K. Taki, and J. Tsujimura. Polym. Eng. Sci., 48, 107 (2008).

18. X. Qin, M.R. Thompson, and A.N. Hrymak. Polym. Eng. Sci., 47, (2007).

19. D. Eaves. Handbook of Polymer Foams, Rapra Technology Limited, United Kingdom (2004).

20. C.A. Villamizar and C.F. Han. Polym. Eng. Sci., 18, 9 (1978).

21. A.K. Bledzki, J. Kühn, H. Kirschling and W. Pitscheneder. Cell. Polym., 27, 2 (2008).

22. A.K. Bledzki, and O. Faru. Macromol. Mater. Eng., 291, (2006)

23. E. Bociaga, and P. Palutkiewicz. Polym. Eng. Sci., 53, 4 (2013).

24. A.K. Bledzki, and O. Faruk. J. of App. Polym. Sci., 97, 3 (2005).

25. Additives for Polymers., 2013, 10 (2013).

26. R. Gosseling, and D. Rodrigue. Polymer testing., 24, (2005). 
27. M. Amon, and C.D. Denson. Polym. Eng. Sci., 24, 13 (1984).

28. J. Bikard, J. Bruchon, T. Coupez and B. Vergnes. J. of Mat. Sci., 40, (2005).

29. J. Bruchon. Thèse de doctorat. Ecole Nationale Supérieure des Mines de Paris.

30. R.J. Koopmans, C.F. Jaap, C. F. den Doelder, and A.N. Paquet. Adv. Mater., 12, 23 (2000).

31. Y. Otsuki, and T. Kanai. Polym. Eng. Sci., 45, (2005).

32. M.A. Shafi, and R.W. Flumerfelt. Chem. Eng. Sci., 52, (1997).

33. M.A. Shafi, J.G. Lee, and R.W. Flumerfelt. Polym. Eng. Sci., 36, (1996).

34. K. Joshi, J.G. Lee, M.A. Shafi, and R.W. Flumerfelt. J. of App. Polym. Sci., 67, (1998).

35. K. Taki. Chem. Eng. Sci., 63 (2008).

36. K. Taki, T. Yanagimoto, E. Funami, M. Okamoto, and M. Ohshima. Polym. Eng Sci., 44, 6 (2004).

37. J.J. Feng, and C.A. Bertelo. J. Rheol., 48, 2 (2004).

38. M. Emami, M.R. Thompson, and J. Vlachopoulos. Polym. Eng Sci., 54, 5 (2014).

39. S. Sourour, and M.R. Kamal. Thermochimica Acta, 14, (1976). 